\title{
Treatment of adults with acute uncomplicated malaria with azithromycin and chloroquine in India, Colombia, and Suriname
}

This article was published in the following Dove Press journal:

Research and Reports in Tropical Medicine

13 October 2017

Number of times this article has been viewed

\author{
Nilima A Kshirsagar' \\ Nithya J Gogtay' \\ Diego Moran ${ }^{2}$ \\ Gregory Utz ${ }^{3}$ \\ Ashok Sethia ${ }^{4}$ \\ Shirsendu Sarkar ${ }^{5}$ \\ Pol Vandenbroucke ${ }^{6}$
}

'Seth G S Medical College and KEM Hospital, Mumbai, India; ${ }^{2}$ Hospital San Andrés de Tumaco, Narino, Colombia; ${ }^{3}$ US Naval Medical Research Unit 6, Lima, Peru; ${ }^{4}$ Gita Bhawan Hospital and Research Centre, Indore, ${ }^{5}$ Pfizer, Mumbai, India; ${ }^{6}$ Pfizer, New York, NY, USA

Correspondence: Pol Vandenbroucke Pfizer Inc., 235 East 42nd Street, New York, NY 10017, USA

Tel + I 212733 III 4

Fax + I $64644 \mid 6527$

Email pol.vandenbroucke@pfizer.com
Background: To explore the use of azithromycin-chloroquine (AZCQ) for the treatment of malaria, we conducted double-blind, randomized, non-inferiority studies in India, Colombia, and Suriname comparing the combination of azithromycin $1 \mathrm{~g}$ and chloroquine (CQ) $600 \mathrm{mg}$ base once daily (QD) for 3 days versus atovaquone-proguanil (AP) or chloroquine plus sulfadoxinepyrimethamine (SPCQ) in adults with acute uncomplicated Plasmodium falciparum malaria.

Methods: Patients were hospitalized until three documented negative blood smears and followed through Day 42. The primary end point was parasitologic cure at Day 28.

Results: In India, parasite clearance rates were $84 \%$ and 94\% for AZCQ and SPCQ, respectively ( $95 \%$ confidence interval $[\mathrm{CI}]$ for the difference: $-22.6,0.8)$. In Colombia and Suriname, parasite clearance rates were $57 \%$ and $99 \%$ for AZCQ and AP, respectively ( $95 \% \mathrm{CI}:-52,-32$ ). A subsequent open-label, non-comparative third study using a $2 \mathrm{~g}$ dose of azithromycin and $600 \mathrm{mg}$ of CQ in India and Colombia resulted in an overall efficacy rate of 97\%.

Conclusion: In India, Colombia, and Suriname, $1 \mathrm{~g}$ azithromycin with CQ QD for 3 days was inferior to established comparator agents. An improved response rate was observed when the dose of azithromycin was increased to $2 \mathrm{~g}$.

Keywords: acute, uncomplicated malaria, antimalarial, azithromycin, chloroquine, malaria, parasitologic cure rate, plasmodium

\section{Introduction}

Although chloroquine (CQ) has served as the cornerstone of therapy for treatment and prevention of malaria for decades, widespread clinical resistance has now led to its removal from therapeutic guidelines for the treatment of Plasmodium falciparum malaria. ${ }^{1}$ Over 50 years of use much has been learned about the safety and efficacy of $\mathrm{CQ}$, especially in vulnerable subpopulations such as pregnant women and children., Although new agents with novel mechanisms of action are needed to replace older antimalarial therapies, numerous efforts have been made to identify strategies that reverse the clinical effects of CQ resistance and extend its useful life until these newer agents become available. ${ }^{4}$ To date, none of these strategies have proved uniformly successful.

Currently licensed antimalarials in India and South America include CQ (India and South America), sulfadoxine-pyrimethamine (SP; India and South America), sulfalene-pyrimethamine (India), artesunate (South America), mefloquine (South America), clindamycin (South America), doxycycline (India), and quinine (India and South America). Increasing resistance, frequency of dosing, and unacceptable side effects are all factors that may compromise use of these agents. More efficacious and 
simpler regimens exist but utilize drugs that are cost prohibitive (e.g., mefloquine and atovaquone-proguanil [AP]).

Azithromycin was utilized in several small studies in combination with artemisinin derivatives for the treatment of uncomplicated falciparum malaria. ${ }^{5-7}$ Results of these studies were consistent with in vitro findings, which failed to demonstrate synergy between azithromycin and artemisinin derivatives.

However, the demonstrated additive to synergistic effects seen in vitro with the coadministration of azithromycin-chloroquine (AZCQ) translated into more encouraging results when studied in the clinical setting.

For several decades, CQ was the most important drug for the treatment of malaria. The emergence and spread of $\mathrm{CQ}$ resistance, however, has meant that other treatments such as artemisinin combination therapies (ACTs) have replaced the use of CQ in some regions. ${ }^{8,9}$ The replacement of CQ by other treatment options in some countries, such as Malawi and Kenya, has led to a resurgence in CQ-sensitive $P$. falciparum strains, presumably because CQ-sensitive strains are not subject to the same negative fitness costs associated with mutant $P$. falciparum chloroquine resistance transporter (pfcrt)-mediated CQ resistance. ${ }^{10-12}$ These findings suggest a continuing role for $\mathrm{CQ}$ as an antimalarial drug, if used in combination, in areas where CQ resistance has reduced. ${ }^{13}$

Azithromycin is an antimicrobial typically used for treatment of respiratory tract infections. ${ }^{14}$ It was noted early in its development to have activity against various plasmodia in vitro and in animal models, as well as in a variety of clinical settings. ${ }^{15}$ Promising activity was also identified in vitro when combined with CQ, leading to a small clinical study that demonstrated encouraging early results. ${ }^{16,17}$

In vitro studies have shown that azithromycin has a halfmaximal inhibitory concentration $\left(\mathrm{IC}_{50}\right)$ value similar to other antibiotics used against malaria. Azithromycin does not appear to exhibit cross-resistance with aminoquinolines, artemisinin derivatives, or quinine in an in vitro $P$. falciparum model. ${ }^{18}$ A study by Gingras and Jensen showed azithromycin to be 10 -fold more potent than erythromycin against a CQ-resistant strain of $P$. falciparum and equipotent against a CQ-sensitive strain. In addition, whereas combinations of $\mathrm{CQ}$ and erythromycin were antagonistic, the combination of AZCQ had an additive effect. ${ }^{19}$ Yeo and Rieckmann ${ }^{20}$ demonstrated that the minimum inhibitory concentrations (MICs) of azithromycin in both CQ-resistant and -sensitive strains decreased over 48-96 hours and concluded that it behaved like other antibiotics in its slow rate of action against $P$. falciparum. In India, azithromycin was tested in vitro against
10 strains of $P$. falciparum (five CQ resistant and five CQ sensitive) and completely inhibited parasite growth in all 10 isolates at the highest concentration $(40 \mu \mathrm{g} / \mathrm{mL}){ }^{21}$

When tested in combination with CQ, azithromycin showed activity ranging from additive to synergistic against eight CQ-resistant $P$. falciparum isolates and exhibited an additive response against two CQ-sensitive strains in vitro in one study. ${ }^{22}$

In vivo studies lend further support to the role of azithromycin as an antimalarial agent. In the Plasmodium berghei murine model, azithromycin was shown to be more active than erythromycin with lower $\mathrm{IC}_{50}$ values against both CQ-resistant and -sensitive strains. ${ }^{23}$ All mice cleared their parasitemia after 3 days of receiving $\mathrm{IC}_{50}$ levels of drug. Azithromycin was also more active than roxithromycin, clarithromycin, erythromycin, and doxycycline in another study using a rodent model with $P$. berghei. ${ }^{24}$

One of the considerations involving the use of azithromycin in the treatment of malaria has been the slower rate of resolution of parasitemia, possibly a consequence of its mechanism of action. The addition of a more rapidly cidal agent to azithromycin had been recommended as a way to optimize its application in a clinical setting. Even though RI resistance (clearance of asexual $P$. falciparum parasitemia before Day 7 followed by recurrence on or after Day 7) occurring between Days 21 and 28 has impacted its utility, CQ has been demonstrated to rapidly reduce the circulating burden of organisms. A combination of AZCQ may therefore be rapidly parasiticidal while reducing the likelihood of breakthrough resistance.

Although antibacterials that act upon protein or nucleic acid synthesis often have significant antimalarial activity, they act relatively slowly and so are often used in combination with more rapidly acting antimalarial agents. For example, although the sulfonamides and sulfones inhibit folate synthesis in plasmodium, they are usually used in combination with pyrimethamine or the anti-malarial biguanides to maximize synergies. The tetracyclines have activity against all species of malaria, and doxycycline is the most widely used drug of this class for both prophylaxis and treatment. Clindamycin has been shown to be as effective as the tetracyclines but has the additional benefit that it can be used in children and pregnant women. Azithromycin is more active and has been evaluated for both prophylaxis and treatment, while rifampicin has a weak antimalarial effect in vivo. There is evidence that chloramphenicol has some antimalarial activity, but this has yet to be well characterized, and despite one promising report of antimalarial activity of 
the fluoroquinolones, subsequent clinical results have been disappointing. Fosmidomycin has shown good antimalarial activity and is under further investigation. ${ }^{25}$

In the Americas, $>80 \%$ of malaria cases originate in the nine countries that share the Amazon rainforest: Bolivia, Brazil, Colombia, Ecuador, French Guiana, Guyana, Peru, Suriname, and Venezuela. While the predominant species of malaria in South America is Plasmodium vivax, almost all the region's cases of $P$. falciparum come from these countries. $P$. falciparum is important for two reasons: 1) mortality due to malaria is commonly associated with $P$. falciparum, and 2) resistance of $P$. falciparum to first-line antimalarials makes treatment complicated.

Peru experienced an alarming increase in the incidence of malaria and in resistance to CQ beginning in the early 1990s. The number of cases in Peru increased from 30,814 in 1989 to 211,561 in $1996 .{ }^{26}$ Before this rapid increase in malaria, $P$. falciparum cases were CQ sensitive and confined to the northwest coastal region with only occasional disease seen in Loreto. ${ }^{27}$ In 1988, there were no cases of $P$. falciparum malaria reported in Loreto, but in 1997, 54,290 blood-smear-confirmed $P$. falciparum cases and 85 deaths were reported. ${ }^{27}$ An in vivo study conducted from January to July 1999 in the coastal department of Tumbes showed RII-RIII resistance to CQ between 53 and 65\%; RII-RIII resistance to SP was as high as $10 \%$. Current treatment recommendations in the North Coast include a combination of SP and artesunate; within Loreto, resistance to chloroquine plus sulfadoxine-pyrimethamine (SPCQ) is common, and the current first-line treatment recommendation is a combination of mefloquine and artesunate (Ministry of Health, Treatment Guidelines).

Colombia has also experienced an overwhelming escalation in malaria cases in the past decade. Malaria can be found in the Pacific Coast region, Amazon region, and central region of Colombia where 18-24 million people are at risk of developing the disease or dying from it. ${ }^{28}$ The number of diagnosed P. falciparum malaria cases increased from 114,000 in 1997 to $\sim 256,000$ in 1998 . The number of cases was reduced in 1999; however, malaria is still an extensive public health problem in Colombia with estimates from 2004 suggesting that $6 \%$ and $19 \%$ of the population were at mesoendemic and hyperendemic risks, respectively. ${ }^{29}$

Although significant progress has been made in the Amazon region of Brazil, ${ }^{30}$ malaria remains a serious health problem. ${ }^{31}$ In all, $95 \%$ of all malaria in Brazil is in the Amazon basin region; P. falciparum malaria displays a high-grade resistance to $\mathrm{CQ} .{ }^{32}$
At the time of the studies described in this report, malaria was considered one of Suriname's worst health problems, since after a period of control in the $60 \mathrm{~s}$ and $70 \mathrm{~s}$, the incidence of malaria increased sharply in the late $80 \mathrm{~s}$. Estimates from 2004 suggest that $6 \%$ of the population were at mesoendemic risk and $0.7 \%$ were at hyperendemic risk. ${ }^{29}$ The areas where incidence had most increased were in the interior where migration of people occurs more frequently. In 2002 , 13,091 cases were reported, a $23 \%$ reduction with respect to 2001 , but there were a number of areas where outbreaks of $P$. falciparum occurred, affecting indigenous communities in the south of the country and near the Afobaka lake. ${ }^{33}$ CQresistant malaria due to $P$. falciparum was widespread, but quinine resistance had not yet been established.

The malaria transmission zone in Venezuela covered 23\% of the country's surface area at the time of these studies. In 2002, 29,337 cases were reported, a 29\% increase over those in 2001. They were primarily concentrated in Sucre, Bolívar, and Amazonas states, followed by Zulia, Barinas, Portuguesa, Apure, and Anzoátegui. Problems identified during the year were associated with migration in mining areas and resistance by strains of $P$. falciparum to the first-line antimalarials. ${ }^{33}$

Increasing rates of resistance of malaria parasites to available antimalarial agents have led to a shift toward the use of combination therapies for malaria treatment in many malaria endemic regions. The combination of AP has demonstrated efficacy in the treatment of uncomplicated $P$. falciparum malaria in South America and was determined to be an appropriate comparator for this study. ${ }^{34}$

Malaria is endemic in most areas of India, which has experienced a resurgence in malaria incidence since the 1970 s. $^{35}$ Estimates from 2004 suggest that $41 \%$ of the population were at mesoendemic risk with $27 \%$ at hyperendemic risk. ${ }^{29}$ The resurgence since the $1970 \mathrm{~s}$ is attributed to a number of factors, including resistance of mosquitoes to pesticides and an increase in CQ-resistant parasites. The proportion of cases of $P$. falciparum, which causes cerebral malaria and is responsible for most of the morbidity and mortality associated with the disease, has increased dramatically in India from $9.34 \%$ in 1972 to $35.5 \%$ in 1995 . Resistance to CQ in P. falciparum malaria is found throughout India and ranges between 15 and $40 \%$; a recent study demonstrated a $64 \%$ rate of CQ resistance in Parel, Mumbai. ${ }^{36}$ Although these cases of resistance may still respond to quinine, its adverse event (AE) profile, which includes cinchonism, hypoglycemia, and cardiac arrhythmias, complicates its use. Nonetheless, quinine is commonly used in the treatment of malaria. 
A previous clinical trial in India demonstrated that a combination of AZCQ was effective as a treatment for $P$. falciparum infection in patients with limited immunity (Study 066-191/191B).${ }^{16}$ After Study 066-191 demonstrated poor activity of either azithromycin or CQ as monotherapy for the treatment of uncomplicated $P$. falciparum malaria at Day 28 (clinical success rates of $33 \%$ vs. $27 \%$ for AZCQ, respectively), the study was modified (Protocol 066-191B) to assess the efficacy of a combination of AZCQ on the resolution of parasitemia, rate of relapse, and toleration. Clinical success was seen in 61/63 (97\%) evaluable patients (95\% confidence interval [CI], 90-99\%) by Day 7, without relapse through Day 28.

As part of a global program to study the activity of the combination of AZCQ for treatment of $P$. falciparum malaria, dose investigation studies were performed in Africa, India, and South America. We report here the results of two randomized, comparative studies: study A0661120 in India and study A0661126 in Colombia and Suriname and a single-arm, open-label study (A0661154) in India and Colombia. Results from studies conducted in Africa are reported separately. ${ }^{37}$

\section{Methods}

The studies were conducted in compliance with the ethical principles originating in or derived from the Declaration of Helsinki (Revised Edinburgh, 2000) and in compliance with institutional review boards or institutional ethics committees (India: independent ethics committee, ethical committee of ISPAT General Hospital, and local ethics committee, Goa; Colombia: Comité de Etica en Investigación del Hospital Funación Santa Fe de Bogotá, Comité de Etica e Investigación Biomédica, and Valle del Cauca; Suriname/US: institutional review board of US Naval Medical Research Center), informed consent regulations, and International Conference on Harmonization Good Clinical Practices Guidelines. In addition, all local regulatory requirements were followed, in particular, those affording greater protection to the safety of trial participants. The clinical protocols were approved by the institutional review boards and ethics committees, and the studies were conducted in accordance with the US Food and Drug Administration regulations. Pfizer Inc. conducted the clinical monitoring of the studies. All participants (or their legally acceptable representatives) provided written informed consent prior to participation.

\section{Study sites}

Study A0661120 (NCT00074841) in India was conducted at investigational sites in six cities: Mumbai, Bambolim
(Goa), Indore, Nagpur, Rourkela, and Guwahati (September 2003 to January 2005). In Colombia and Suriname, study A0661126 (NCT00084227) was conducted in Paramaribo, Suriname, and three cities in Colombia, specifically Guapi, Tumaco, and Tadó (July 2004 to July 2005). Study A0661154 (NCT00282919) was conducted in Goa (India) and Tumaco (Colombia) during March 2006 to February 2008.

\section{Study population}

Eligible patients were $\geq 18$ years of age with uncomplicated, symptomatic malaria as demonstrated by blood smears positive for $P$. falciparum asexual parasitemia between 1,000 and 100,000 parasites $/ \mu \mathrm{L}$ and either documented fever $\left(\geq 38.5^{\circ} \mathrm{C} / 101.3^{\circ} \mathrm{F}\right.$ rectal or tympanic, $\geq 37.5^{\circ} \mathrm{C} / 99.5^{\circ} \mathrm{F}$ axillary, or $\geq 38^{\circ} \mathrm{C} / 100.4^{\circ} \mathrm{F}$ oral) or history of fever within the prior 24 hours. Patients were also required to have a serum glucose $\geq 60 \mathrm{mg} / \mathrm{dL}$ (by finger stick or peripheral blood collection) and a rapid diagnostic test (BinaxNOW ${ }^{\circledR}$ ICT; Alere, Scarborough, ME, USA) positive for P. falciparum. Patients were excluded for any of the following reasons: clinical or laboratory evidence of severe or complicated malaria (adapted from the 1990 World Health Organization definition of severe malaria), ${ }^{38}$ pregnancy or breast feeding; history of allergy or hypersensitivity to azithromycin, any macrolide, or the relevant study drugs; history of epilepsy or psoriasis; treatment with any antimalarial drug or with any antibacterial with known antimalarial activity within 2 weeks prior to enrollment; impaired renal function; alanine aminotransferase and/or aspartate aminotransferase $>3 \times$ upper limit of normal; inability to swallow oral medication in tablet form; treatment with other investigational drugs within 30 days prior to enrollment in the study; alcohol and/or any other drug abuse; requirement to use medication during the study that might interfere with the evaluation of the study drug; specific systemic diseases or other medical conditions that would interfere with the evaluation of the therapeutic response or safety of the study drug; inability to comprehend and/or unwillingness to follow the study protocols; or prior participation in these studies. Patients in India were also excluded for known or suspected folate deficiency or known history of glucose-6-phosphate dehydrogenase (G6PD) deficiency or other hematologic abnormalities. Women of childbearing potential were required to have a negative urine gonadotropin test prior to study entry and were to use adequate contraception during study participation.

Patients were withdrawn from the studies and placed on rescue therapy for any of the following reasons: impaired consciousness, respiratory distress, seizures, hypoglycemia, 
gross hematuria, increase in parasitemia to $>100,000$ parasites $\mu \mathrm{L} \geq 24$ hours (48 hours in study A0661154) after the first treatment dose, investigator opinion that other antimalarial therapy was indicated, treatment failure, or vomiting after repeated study dosing (study A0661154).

Rectal, tympanic, axillary, or oral methods of temperature recording may have been used at baseline to establish the presence of fever. Fever was defined as $\geq 38.5^{\circ} \mathrm{C} / 101.3^{\circ} \mathrm{F}$ rectal or tympanic, $\geq 37.5^{\circ} \mathrm{C} / 99.5^{\circ} \mathrm{F}$ axillary, $\geq 38^{\circ} \mathrm{C} / 100.4^{\circ} \mathrm{F}$ oral, or history of fever (as reported by subjects) within the prior 24 hours. During the trials, fever clearance was only defined using axillary or oral temperature and was defined as $<37.5^{\circ} \mathrm{C} / 99.5^{\circ} \mathrm{F}$ axillary or $<38^{\circ} \mathrm{C} / 100.4^{\circ} \mathrm{F}$ oral.

Routine testing for G6PD deficiency was not undertaken in these studies. However, patients with known history of G6PD deficiency were excluded from the clinical trial A0661120, as it used SP as an active comparator. Although screening for G6PD deficiency is not required prior to treatment with SP, patients with a known history of G6PD should not receive SP because of the risk of hemolytic anemia.

\section{Drug treatment}

In study A0661120 in India, eligible patients were randomized to oral treatment for 3 days (Days 0-2) in one of three active treatment arms: azithromycin $1 \mathrm{~g}$ plus CQ $600 \mathrm{mg}$ base (AZCQ $1 \mathrm{~g}$ ) once daily (QD) for 3 days, azithromycin $500 \mathrm{mg}$ plus CQ $600 \mathrm{mg}$ base (AZCQ $500 \mathrm{mg}$ ) QD for 3 days, or SP $(500 \mathrm{mg} / 25 \mathrm{mg})$, three tablets, for a total of $1,500 \mathrm{mg} / 75 \mathrm{mg}$ plus CQ $600 \mathrm{mg}$ QD on Days 0 and 1 plus chloroquine $300 \mathrm{mg}$ on Day 2. Azithromycin doses were blinded, while SP and CQ doses were administered open label.

In study A0661126 in Colombia and Suriname, the AZCQ regimens were as described for India but the comparator agent was AP $250 \mathrm{mg} / 100 \mathrm{mg}$ given as four capsules QD for 3 days. In this trial, study drug was administered as blinded therapy with matching placebo. Full doses of study drug were readministered if the patient vomited within 30 minutes of administration. If vomiting recurred, the subject was discontinued from the study.

In the non-comparative study in Goa and Tumaco (study A0661154), patients received $2 \mathrm{~g}$ azithromycin and $600 \mathrm{mg}$ base CQ QD for 3 days; both drugs were administered orally.

In the randomized studies (A0661120 and A0661126), the sponsor provided a computer-generated randomization list to each investigator, who then assigned patient numbers sequentially to patients as they were deemed eligible for treatment. Patients received study medication assigned to the corresponding number. Treatment allocation was 1:1:1, with a block size of six. In the nonrandomized study (A0661154), eligible patients received open-label therapy.

\section{Parasite identification}

The blood dipstick-based test BinaxNOW ${ }^{\circledR}$ ICT was used for rapid diagnostic testing of $P$. falciparum. The BinaxNOW ICT malaria test identifies the histidine-rich protein II antigen, specific to $P$. falciparum; it also identifies a pan-malarial antigen common to $P$. falciparum, $P$. vivax, Plasmodium ovale, and Plasmodium malariae. ${ }^{39}$ Monoinfection with $P$. falciparum was confirmed by microscopy. Giemsa-stained blood smears were read and interpreted by trained and certified microscopists who were blinded to all clinical information, including treatment allocation (in the two randomized studies). Three smears were prepared for each patient; two of these were read locally at each investigational site in a blinded manner, while the third slide was maintained for possible third-party review in the event of discrepancies. Thick and thin smears were prepared for parasite counts every 8 hours until three consecutive smears were negative, then on Day 7 , and weekly until the end of the study (Day 42). Unscheduled smears were obtained for subjects presenting with signs and/or symptoms suggestive of malaria at any time during follow-up. All smears were read in a blinded manner (blinded to clinical information and reading of other microscopists) and were preserved for possible third party confirmation.

Parasite densities were determined by counting the number of asexual $P$. falciparum parasites until 200 leukocytes were observed and then converting that figure to parasites per microliter of blood, assuming an average leukocyte count of $8,000 / \mu \mathrm{L}$. An average of 8,000 leukocytes $/ \mu \mathrm{L}$ was considered as standard. Despite inaccuracies due to variations in the number of leukocytes between individuals in normal health and greater variations in ill-health, this standard allows for reasonable comparisons and was recommended by the World Health Organization (WHO) at the time of these studies. ${ }^{40}$ Smears were reported as negative if no parasites were seen in at least 200 high-power fields. Smear results at the site guided patient management, and any patient with persistent or recurrent parasitemia during the follow-up period was treated with antimalarial drugs according to local treatment guidelines. Patients treated with additional antimalarial drugs were withdrawn from further participation in the study following documented clearance of parasitemia.

In patients who developed asexual parasitemia after a period of clearance, paired blood blots (from baseline and the time of recurrence) were analyzed for parasite merozoite surface protein (MSP-2) genotyping to distinguish recrudescence 
(treatment failure) from reinfection. Recrudescence was defined as reappearance of asexual blood stage parasites of the same genotype as Day 0 parasites, while reinfection was defined as infection by a different genotype. Patients were censored at the time of reinfection.

Genotyping was performed by the Naval Medical Research Unit-2 (NAMRU-2; Jakarta, Indonesia). The MSP-2 gene was amplified using nested polymerase chain reaction (PCR), as described elsewhere. ${ }^{41}$ Testing for genetic markers of CQ resistance was also performed..$^{42}$ Paired blood specimens, collected at baseline and at the time of failure, were evaluated for the pfcrt gene. In addition, specimens collected on Day 0 from patients who responded to treatment were also analyzed for $p f c r t$ gene mutations. A quantitative PCR was to be performed from baseline through the time of parasite clearance and, if parasitemia recurred, at the time of recurrence in a subset of subjects.

\section{Gametocyte evaluation}

Thick and thin smears were prepared for quantification of gametocytemia on Days 7, 14, 21, 28, 35, and 42. Clearance was defined as attainment of three consecutive 0 gametocyte counts without subsequent recurrence through the day of consideration. "No clearance" was defined as failure to achieve clearance of $P$. falciparum gametocytemia or subsequent recurrence through the day of consideration after achieving clearance.

Gametocyte density was estimated by counting the number of gametocytes per 200 leukocytes in the thick blood smear. Parasite count in relation to total leukocyte count (TLC) was then converted to parasites per microliter using the following formula: (no. of parasites $\times 8,000) /($ no. of leukocytes).

\section{Study assessments}

All patients were hospitalized and monitored for a minimum of 3 days until three consecutive blood smears, obtained at 8-hour intervals, were negative for asexual parasites and the investigator deemed discharge from the hospital was appropriate. Vital signs, clinical signs and symptoms, AEs, and concomitant medications were assessed for all patients on each day of treatment and at each weekly posttherapy visit through Day 42. Peripheral blood smears for parasite counts were obtained at 8-hour intervals until clearance was demonstrated, then on Day 7, and weekly thereafter through Day 42. Test of cure was performed at Day 28. Hematology and serum chemistry laboratory tests were performed at baseline and Day 3 and at subsequent visits if clinically indicated.

\section{Efficacy}

The primary efficacy analysis was assessment of the asexual P. falciparum parasite clearance rate at Day 28 in the evaluable population, also referred to as parasitological per protocol population, which consisted of patients meeting the following criteria: blood smears positive for $P$. falciparum monoinfection, asexual parasitemia between 1,000 and 100,000 parasites per microliter, fever or history of fever within the preceding 24 hours, positive rapid diagnostic test for P. falciparum, and received all 3 days of study medication.

Patients were assigned a response of "cleared" if parasitemia cleared within 7 days of initiation of treatment and did not recur through Day 28. Failure was defined as failure to achieve clearance of asexual P. falciparum parasitemia within 7 days of initiation of treatment or subsequent recurrence by Day 28 after achieving clearance. Patients who received other antimalarial medication effective against $P$. falciparum on or before the analysis time point were considered failures.

Secondary efficacy analyses included asexual parasite clearance time, fever clearance time, and sponsor assessment of the percentage of patients with early treatment failure (ETF) and late treatment failure (LTF). Patients were considered ETFs if they developed signs of severe malaria on Days 1,2 , or 3 in the presence of parasitemia; had an increase from the baseline parasite count on Day 2, irrespective of axillary or oral temperature; had parasitemia on Day 3 with an axillary or oral temperature $\geq 37.5^{\circ} \mathrm{C} / 99.5^{\circ} \mathrm{F}$; or had a parasite count on Day 3 that was $\geq 25 \%$ of first available count at baseline. The use of other antimalarial drugs for the purpose of treating malarial infection any time from Days 0 to 3 was considered as ETF. LTF was categorized as either clinical or parasitologic. Patients were considered as a late clinical failure (LCF) if they developed signs of severe malaria between Days 4 and 28 in the presence of $P$. falciparum parasitemia or if they developed $P$. falciparum parasitemia and fever/ history of fever or without fever on any day between Days 4 and 28. Late parasitological failure (LPF) was defined as the presence of parasitemia on any day from Days 7 to 28 and the absence of fever or without previously meeting any of the criteria of ETF or LCF. The use of other antimalarial drugs for the purpose of treating malarial infection any time from Days 4 to 28 was considered evidence of LTF.

\section{Safety}

All patients who received at least one dose of study medication were evaluated for safety. Patients were monitored for clinical evidence of illness progression. All patients with persistent or recurrent parasitemia received rescue therapy consistent with 
the local standard of care. All observed or volunteered AEs were recorded, together with an assessment of event severity (mild, moderate, or severe), seriousness, and an opinion of the event's relationship to study therapy, and were managed in accordance with the local standard of care. AEs included adverse drug reactions and illnesses that began during the study, as well as exacerbations of previous illnesses. A serious $\mathrm{AE}$ was defined according to the International Conference on Harmonization (ICH E6, Glossary 1.50).

\section{Sample size calculations and statistical methods}

For analyses of the primary efficacy end point in the comparative studies (A0661120 and A0661126), 95\% two-sided CIs were constructed for the difference in asexual parasite clearance rates using normal approximation to the binomial. Non-inferiority was to be concluded if the lower boundary of the $95 \% \mathrm{CI}$ for the difference in cure rates was $\geq-10 \%$. If the $1 \mathrm{~g} \mathrm{AZCQ}$ arm was non-inferior to the comparator, the $500 \mathrm{mg}$ AZCQ arm was to be similarly compared with the comparator for non-inferiority. Sample sizes of 258 patients in the Indian study and 234 patients in the Colombia and Suriname studies were determined based on the power to show non-inferiority relative to the comparator (India, 90\%; Colombia and Suriname, 80\%), an evaluability rate of $85 \%$ at Day 28, and expected cure rates (AZCQ, 95\%; SPCQ, 90\%; AP, 95\%).

For the non-comparative study (A0661154), a two-sided 90\% CI for parasite clearance was constructed using normal approximation to the binomial with continuity correction. A sample size of 110 subjects was determined based on an expected cure rate of $95 \%$ and an evaluability rate of $90 \%$ at Day 28.

For the comparative studies, interim analyses were conducted and additional unplanned reviews of the data were anticipated by the Data Safety Monitoring Board (DSMB), an independent group of experts who advise study investigators and review protocols prior to implementation. The objective of the interim analysis in the comparative India and Colombia and Suriname studies was to test for inadequate efficacy of the $\mathrm{AZ}$ combination arm. A group sequential procedure with Gamma spending function and parameter values of -4 (India) or -8 (Colombia and Suriname) was used to determine the confidence levels for all such analyses. The interim analysis for the India study was conducted after 96 patients ( $-32 / \mathrm{arm})$ were enrolled and was based on assumptions of an evaluability rate of $95 \%$ corresponding to the Day 7 visit, an expected cure rate $\geq 90 \%$ for the comparator and $\geq 30 \%$ difference between treatments, and a power of $\geq 80 \%$ to show inferiority of the $500 \mathrm{mg}$ AZCQ arm, defined as the upper limit of the one-sided $95 \%$ exact binomial CI being below zero. The final analysis was tested for non-inferiority by using a $95 \%$ two-sided CI. Based on the results of the interim analysis, the study design could have been modified to exclude the $500 \mathrm{mg}$ AZCQ arm if it was inadequately efficacious or terminated if both AZCQ arms were ineffective. No conclusions for superiority of the azithromycin arms were to be made based on the interim analysis results.

In the Colombia and Suriname study, a sample size of 35 patients per group for the interim analysis was determined based on assumptions of an evaluability rate of $85 \%$ corresponding to the Day 28 visit (resulting in 30 patients in each treatment arm), an expected cure rate of $\geq 95 \%$ in the AP arm and a $\geq 30 \%$ difference between treatments, and a power of $\geq 80 \%$ to show inferiority of the $1 \mathrm{~g}$ AZ combination arm, defined as the upper limit of the one-sided 95\% exact binomial CI being below zero.

Programs prepared by the sponsor were provided to a contract research organization (CRO), Synectechs Inc. (New London, CT, USA), which unblinded the data, ran the tables, and sent the output to the DSMB members. All appropriate steps were taken to ensure that the blind was not broken for the sponsor.

For secondary efficacy end points, comparisons of asexual parasite clearance rates and gametocyte clearance rates at various time points as well percentages of ETF and LTF were estimated by constructing CIs ( $95 \%$ for the comparative studies and $90 \%$ for the open-label study) using normal approximation to the binomial distribution. Comparisons of asexual parasite clearance times and fever clearance times used the life table method. Parasite clearance time was defined as the time from baseline to first of the three consecutive zero parasite counts. Fever clearance time was defined as the time from baseline to the first of the two consecutive time points with temperature $<37.5^{\circ} \mathrm{C}$. Differences in ETF and LTF were estimated by constructing $95 \%$ CIs using normal approximation to the binomial distribution.

\section{Results Comparative studies: demographics and disposition}

The demographic and baseline characteristics of patients enrolled into each regimen were evenly matched (Table 1). In the Indian study (A0661120), the majority of patients were young men, whereas the study in Colombia and Suriname (A0661126) included more balanced proportions of men and 
Table I Patient demographics from studies A066 I 20 (India), A066 I I 26 (Colombia/Suriname), and A066 I I54 (Colombia/India)

\begin{tabular}{|c|c|c|c|}
\hline India (A066 I I 20) & AZCQ I g & AZCQ 500 mg & SPCQ \\
\hline Randomized & 83 & 67 & 80 \\
\hline Male & 68 & 61 & 70 \\
\hline Female & 15 & 6 & 10 \\
\hline \multicolumn{4}{|l|}{ Age, years } \\
\hline $18-44$ & 68 & 61 & 65 \\
\hline $45-64$ & 14 & 6 & 15 \\
\hline$\geq 65$ & I & 0 & 0 \\
\hline Mean (SD) & $31.7(12.9)$ & $29.5(9.6)$ & $31.7(11.1)$ \\
\hline Range & $18-75$ & $18-58$ & $18-60$ \\
\hline \multicolumn{4}{|l|}{ Weight, kg } \\
\hline Mean (SD) & $54.0(9.1)$ & $54.7(11.8)$ & $55.1(9.9)$ \\
\hline Range & $39.0-76.0$ & $32.0-95.0$ & $35.0-80.0$ \\
\hline Baseline parasite count $/ \mu \mathrm{L}$, mean & $|7,02|$ & 19,232 & $|9,86|$ \\
\hline \multicolumn{4}{|l|}{ Episodes of malaria in previous 2 years } \\
\hline 0 & 71 & 56 & 71 \\
\hline 1 & 12 & 9 & 8 \\
\hline 2 & 0 & 2 & 0 \\
\hline 3 & 0 & 0 & 1 \\
\hline Colombia/Suriname (A066 I I 26) & AZCQ I g & AZCQ $500 \mathrm{mg}$ & AP \\
\hline Randomized & 114 & 14 & 116 \\
\hline Male & 66 & 9 & 64 \\
\hline Female & 48 & 5 & 52 \\
\hline \multicolumn{4}{|l|}{ Age, years } \\
\hline $18-44$ & $88(77.2)$ & $8(57.1)$ & $94(81.0)$ \\
\hline $45-64$ & $22(19.3)$ & $5(35.7)$ & $21(18.1)$ \\
\hline$\geq 65$ & $4(3.5)$ & $\mathrm{I}(7.1)$ & $I(0.9)$ \\
\hline Mean (SD) & $34.6(13.9)$ & $4 I .4(12.3)$ & $33.6(11.8)$ \\
\hline Range & $18-86$ & $24-68$ & $18-74$ \\
\hline \multicolumn{4}{|l|}{ Race } \\
\hline Black & $104(91.2)$ & $10(7 \mid .4)$ & $103(88.8)$ \\
\hline Asian & I $(0.9)$ & 0 & $I(0.9)$ \\
\hline Others & $9(7.9)$ & $4(28.6)$ & $12(10.3)$ \\
\hline \multicolumn{4}{|l|}{ Weight (kg) } \\
\hline Mean (SD) & $66.0(12.3)$ & $72.2(13.8)$ & $67.2(11.7)$ \\
\hline Range & $45.0-96.0$ & $51.0-102.0$ & $43.0-100.0$ \\
\hline Baseline parasite count $/ \mu \mathrm{L}$, mean & 10,324 & 11,191 & 10,412 \\
\hline \multicolumn{4}{|l|}{ Episodes of malaria in previous 2 years } \\
\hline 0 & 71 & 8 & 83 \\
\hline I & 26 & 3 & 17 \\
\hline 2 & 5 & 0 & 7 \\
\hline 3 & 5 & 2 & 6 \\
\hline Colombia/India (A066 I I 54) & AZCQ $2 \mathrm{~g}$ & & \\
\hline Randomized & 110 & & \\
\hline Male & 85 & & \\
\hline Female & 25 & & \\
\hline \multicolumn{4}{|l|}{ Age, years } \\
\hline $18-44$ & $93(84.5)$ & & \\
\hline $45-64$ & $14(12.7)$ & & \\
\hline$\geq 65$ & $3(2.7)$ & & \\
\hline Mean (SD) & $30.8(13.0)$ & & \\
\hline Range & $18-77$ & & \\
\hline \multicolumn{4}{|l|}{ Race } \\
\hline Black & $52(47.3)$ & & \\
\hline Asian & $55(50.0)$ & & \\
\hline Others & $3(2.7)$ & & \\
\hline \multicolumn{4}{|l|}{ Weight (kg) } \\
\hline Mean (SD) & $59.7(14.3)$ & & \\
\hline Range & $35.0-108.0$ & & \\
\hline
\end{tabular}


Table I (Continued)

\begin{tabular}{|c|c|c|c|}
\hline India (A066 I I 20) & AZCQ I g & AZCQ $500 \mathrm{mg}$ & SPCQ \\
\hline Baseline parasite count $/ \mu \mathrm{L}$, mean & - & & \\
\hline \multicolumn{4}{|c|}{ Episodes of malaria in previous 2 years } \\
\hline 0 & 77 & & \\
\hline 1 & 25 & & \\
\hline 2 & 5 & & \\
\hline 3 & 3 & & \\
\hline
\end{tabular}

Note: Values are $n$ unless otherwise noted.

Abbreviations: AP, atovaquone-proguanil; AZCQ, azithromycin-chloroquine; SD, standard deviation; SPCQ, chloroquine plus sulfadoxine-pyrimethamine

women. More patients in the AZCQ arms discontinued the study versus the comparator arms (Table 2 and Figure 1). Lack of efficacy was the most frequent reason for discontinuation in the AZCQ treatment arms.

\section{Efficacy}

The India comparative study (A066 I I20)

In the first preplanned interim analysis on 90 patients, on April 29, 2004, the DSMB recommended continuing all three arms in the study. The second interim review of the data was requested by the DSMB when 190 patients had been enrolled (evaluating 156 patients). In this second analysis, AZCQ $500 \mathrm{mg}$ was shown to be less efficacious than the comparator in asexual parasite clearance (66.1\% vs. $94.4 \%)$ and was therefore subsequently discontinued on October 28, 2004, as per the DSMB recommendation. The study continued in an open-label manner with AZCQ $1 \mathrm{~g}$ and SPCQ. In the final study analysis, the asexual parasite clearance rate for AZCQ $1 \mathrm{~g}$ was $83.6 \%(61 / 73)$ and for SPCQ was $94.4 \%$ (68/72; Table 3$)$. The lower limit of the $95 \% \mathrm{CI}$ fell below the prespecified criteria for non-inferiority of $-10 \%$ (difference $[95 \% \mathrm{CI}]:-10.9[-22.6$, 0.8]). Therefore, non-inferiority was not met.

Table 2 Patient disposition from studies A066 I 20 (India), A066 I I 26 (Colombia/Suriname), and A066 I I54 (Colombia/India)

\begin{tabular}{|c|c|c|c|}
\hline India (A066 I I 20) & AZCQ I g & AZCQ $500 \mathrm{mg}$ & SPCQ \\
\hline Treated & 83 & 67 & 80 \\
\hline Completed & $59(71 \%)$ & $38(57 \%)$ & $70(88 \%)$ \\
\hline Discontinued & $24(29 \%)$ & $29(43 \%)$ & $10(13 \%)$ \\
\hline \multicolumn{4}{|l|}{ Reason for discontinuation } \\
\hline Lack of efficacy & $14(17 \%)$ & $21(31 \%)$ & $3(4 \%)$ \\
\hline Lost to follow-up & $7(8 \%)$ & $7(10 \%)$ & $3(4 \%)$ \\
\hline $\mathrm{AE}$ & $3(4 \%)$ & 0 & I (I\%) \\
\hline Others & 0 & I (2\%) & $3(4 \%)$ \\
\hline PPP population at Day 28 & $73(88 \%)$ & $59(88 \%)$ & $72(90 \%)$ \\
\hline Colombia/Suriname (A066 I I 26) & AZCQ I g & AZCQ $500 \mathrm{mg}$ & AP \\
\hline Treated & 114 & 14 & 116 \\
\hline Completed & $59(52 \%)$ & $3(21 \%)$ & $108(93 \%)$ \\
\hline Discontinued & $55(48 \%)$ & II (79\%) & $8(7 \%)$ \\
\hline \multicolumn{4}{|l|}{ Reason for discontinuation } \\
\hline Lack of efficacy & 37 (33\%) & $8(57 \%)$ & 0 \\
\hline Lost to follow-up & 0 & I (7\%) & $4(3 \%)$ \\
\hline $\mathrm{AE}$ & $4(4 \%)$ & 0 & I (I\%) \\
\hline Others & $13(11 \%)$ & $2(14 \%)$ & $3(3 \%)$ \\
\hline PPP population at Day 28 & $112(98 \%)$ & II (79\%) & $113(97 \%)$ \\
\hline Colombia/India (A066 I I 54) & AZCQ 2 g & & \\
\hline Treated & 110 & & \\
\hline Completed & 103 (94\%) & & \\
\hline Discontinued & $7(6 \%)$ & & \\
\hline \multicolumn{4}{|l|}{ Reason for discontinuation } \\
\hline Lack of efficacy & $4(4 \%)$ & & \\
\hline Lost to follow-up & 0 & & \\
\hline $\mathrm{AE}$ & 0 & & \\
\hline Others & $3(3 \%)$ & & \\
\hline PPP population at Day 28 & 107 (97\%) & & \\
\hline
\end{tabular}

Note: Values are $n$ unless otherwise noted.

Abbreviations: AE, adverse event; AP, atovaquone-proguanil; AZCQ, azithromycin-chloroquine; PPP, parasitologic per protocol; SPCQ, chloroquine plus sulfadoxinepyrimethamine. 
Study A0661120 India

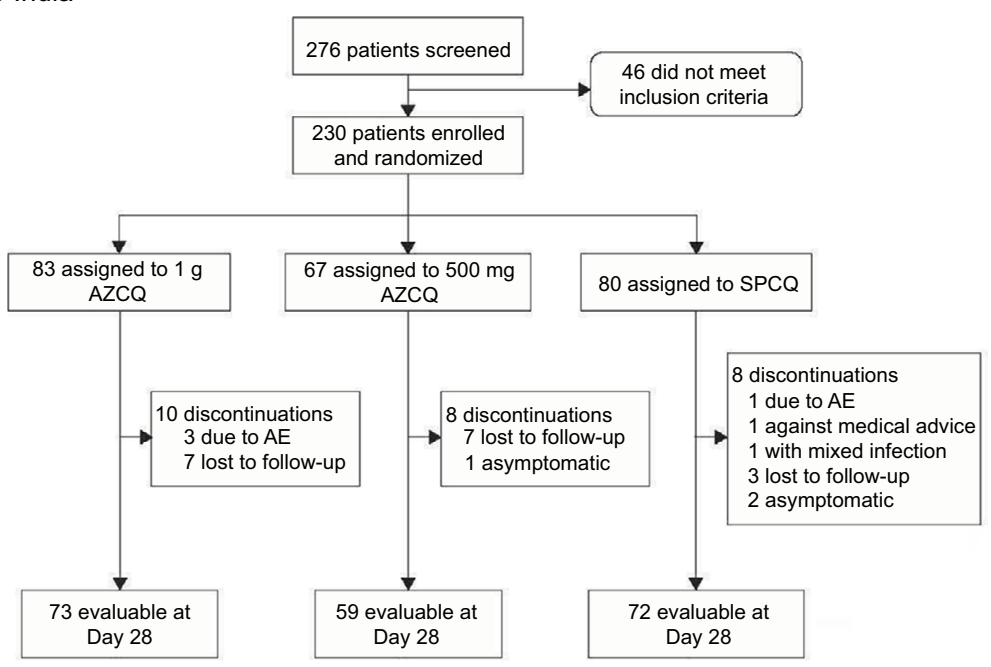

Study A0661126 Colombia/Suriname

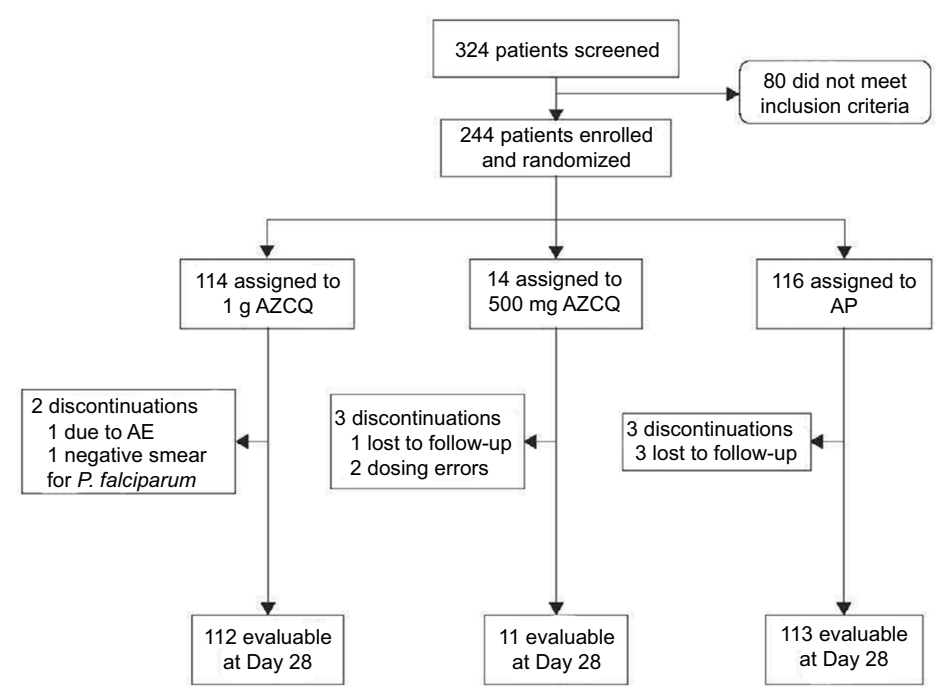

A0661154 Colombia/India

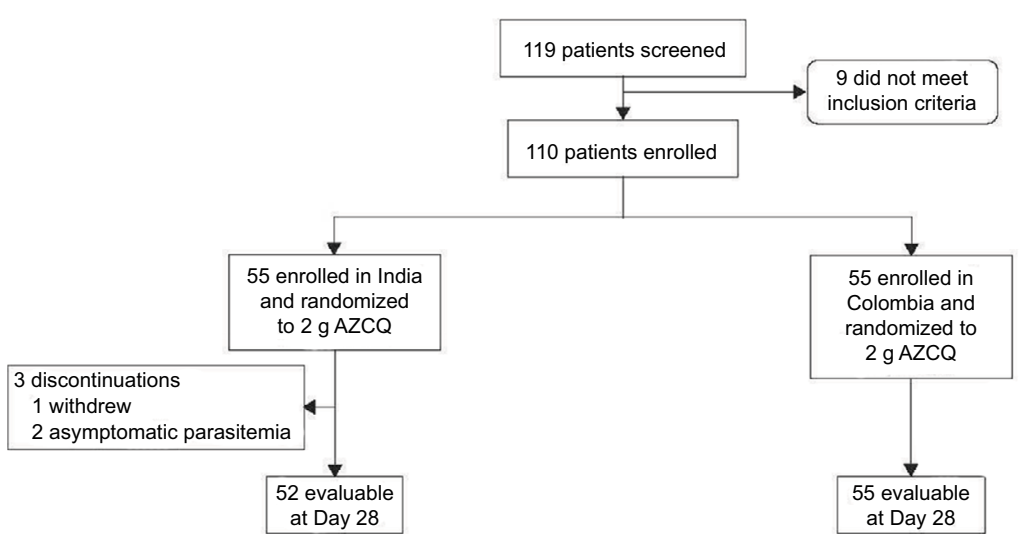

Figure I Number of patients treated and analyzed by treatment group in studies A066 I I 20 (India), A066 I I 26 (Colombia/Suriname), and A066 I I54 (Colombia/India). Abbreviations: AE, adverse event; AZCQ, azithromycin-chloroquine; P. falciparum, Plasmodium falciparum; SPCQ, chloroquine plus sulfadoxine-pyrimethamine.

Treatment failures on AZCQ $1 \mathrm{~g}$ were evenly divided between early $(8.2 \%)$ and late $(8.2 \%)$, whereas the failures on AZCQ $500 \mathrm{mg}$ mostly occurred late $(23.7 \%$ late vs. $10.2 \%$ early).
Asexual parasite clearance occurred earlier in the SPCQ treatment group compared with that in the AZCQ $1 \mathrm{~g}$ treatment group and the AZCQ $500 \mathrm{mg}$ treatment group (Figure 2). There was an increase in the mean log of parasite counts in 
Table 3 Clinical and parasitologic response at Day 28 in studies A066 II20 (India), A066 I I26 (Colombia/Suriname), and A066 I I54 (Colombia/India)

\begin{tabular}{|c|c|c|c|c|c|c|c|}
\hline & \multicolumn{3}{|c|}{ India (A066 I I 20) } & \multicolumn{3}{|c|}{ Colombia/Suriname (A066 I I 26) } & \multirow{2}{*}{$\frac{\text { Colombia/India (A066 I I 54) }}{\text { AZCQ } 2 \mathrm{~g}}$} \\
\hline & AZCQ I g & $\begin{array}{l}\text { AZCQ } \\
500 \mathrm{mg}\end{array}$ & SPCQ & AZCQ I g & $\begin{array}{l}\text { AZCQ } \\
500 \mathrm{mg}\end{array}$ & AP & \\
\hline Randomized, $\mathrm{n}$ & 83 & 67 & 780 & 114 & 14 & 116 & 110 \\
\hline Cleared/evaluable, n (\%) & $61 / 73(84)$ & $39 / 59(66)$ & $68 / 72(94)$ & $66 / 112(59)$ & $4 / 11(36)$ & $112 / 113(99)$ & 104/107 (97) \\
\hline $\begin{array}{l}\text { AZCQ } 500 \text { mg - comparator; } \\
\text { difference, \% }(95 \% \mathrm{Cl})\end{array}$ & \multicolumn{3}{|c|}{$-28.3(-43.5,-13.2)$} & \multicolumn{3}{|l|}{$\mathrm{NA}^{\mathrm{a}}$} & NA \\
\hline $\begin{array}{l}\text { AZCQ I g - comparator; } \\
\text { difference, \% }(95 \% \mathrm{Cl})\end{array}$ & \multicolumn{3}{|c|}{$-10.9(-22.6,0.8)$} & \multicolumn{3}{|c|}{$-42.0(-52.2,31.7)$} & NA \\
\hline ETF, n (\%) & $6(8)$ & $6(10)$ & $I(I)$ & $12(11)$ & & $I(I)$ & 0 \\
\hline LTF, n (\%) & $6(8)$ & $14(24)$ & $3(4)$ & $37(33)$ & & $\mathrm{I}(\mathrm{I})$ & $3(3)$ \\
\hline LPF (Day 28), n & 3 & 8 & 2 & 27 & & 0 & 1 \\
\hline LCF (Day 28), n & 2 & 6 & I & 10 & & 0 & 2 \\
\hline
\end{tabular}

Note: aStatistical comparison between $500 \mathrm{mg} \mathrm{AZCQ}$ and AP was not performed due to the decision to discontinue the AZCQ $500 \mathrm{mg}$ arm.

Abbreviations: AP, atovaquone-proguanil; AZCQ, azithromycin-chloroquine; Cl, confidence interval; ETF, early treatment failure; LCF, late clinical failure; LPF, late parasitological failure; LTF, late treatment failure; NA, not applicable; SPCQ, chloroquine plus sulfadoxine-pyrimethamine.

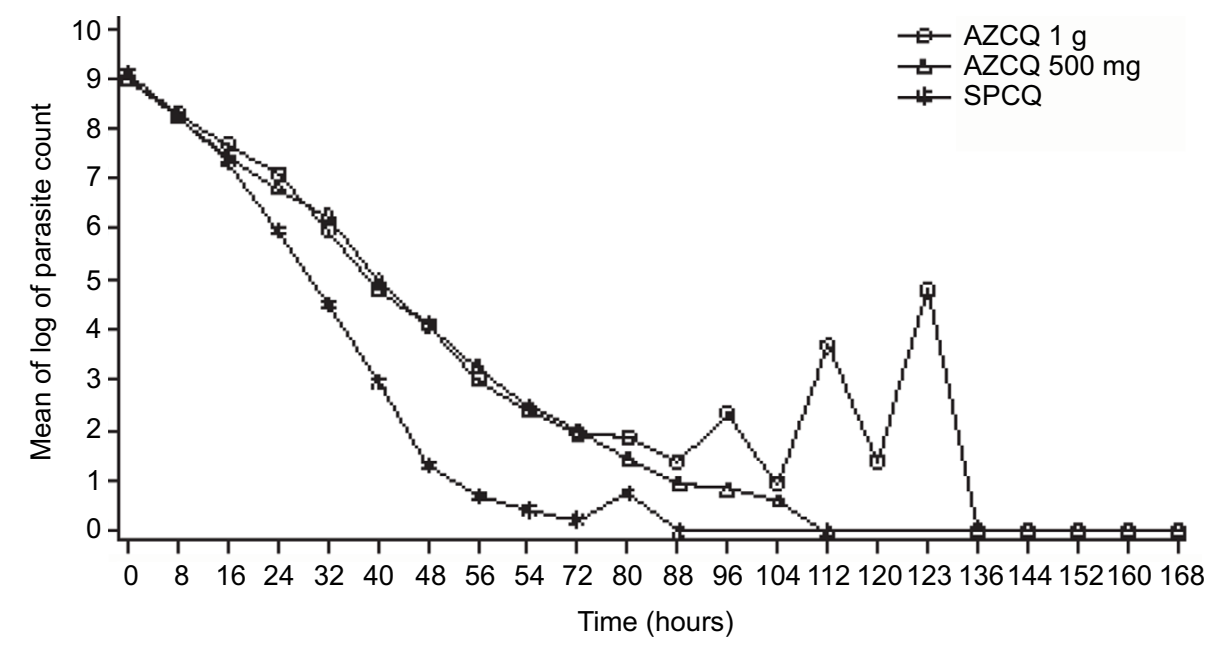

Figure 2 Parasite reductions in patients receiving AZCQ I g, AZCQ 500 mg, or SPCQ in study A066I I 20 (India). Abbreviations: AZCQ, azithromycin-chloroquine; SPCQ, chloroquine plus sulfadoxine-pyrimethamine.

the 1,000 mg AZCQ group on Days 4 and 5, relative to the mean log of parasite counts in the $500 \mathrm{mg}$ AZCQ treatment group. By Days 6 and 7, the mean log of parasite counts of all three treatment groups appeared to be similar. The cumulative proportion of parasitemic subjects up to Day 7 is shown in Figure 3. Taken together, Figures 2 and 3 suggest that the elevated parasite counts in the 1,000 mg AZCQ group on Days 4 and 5 were driven by a single subject with a high burden of disease (see hours 96, 112, 120, and 128) and there were proportionally fewer parasitemic subjects in the 1,000 mg AZCQ treatment group compared with the $500 \mathrm{mg}$ AZCQ treatment group during this period.

The time to resolution of fever was similar between the two AZCQ treatment groups and the SPCQ treatment group (Figure 4). The similarity in fever clearance despite dissimilarity in parasite clearance may be explained by the anti-inflammatory and immunomodulatory effects of azithromycin, which have also been observed in other macrolide antibiotics. In addition, the use of fever-reducing concomitant medications across all treatment groups may in part explain this effect. The most commonly used concomitant medications were analgesics, used by $65.1 \%, 62.7 \%$, and $58.8 \%$ of subjects in the AZCQ $1 \mathrm{~g}$, AZCQ $500 \mathrm{mg}$, and SPCQ treatment groups, respectively. Because these drugs have antipyretic effects, comparisons of fever clearance rates with parasite clearance rates are difficult.

The proportion of patients with clearance of gametocytes at Day 7 did not differ between the AZCQ and SPCQ regimens (Table 4) although time to clearance may have been marginally faster for the AZCQ $1 \mathrm{~g}$ versus the AZCQ $500 \mathrm{mg}$ regimens (rate of clearance $86.3 \%$ vs. $78.3 \%, p=0.051$ ).

A dose-response relationship was observed between the AZCQ groups ( $1 \mathrm{~g}$ and $500 \mathrm{mg}$ ) in the comparative studies A00661120 and A0661126. The difference in 


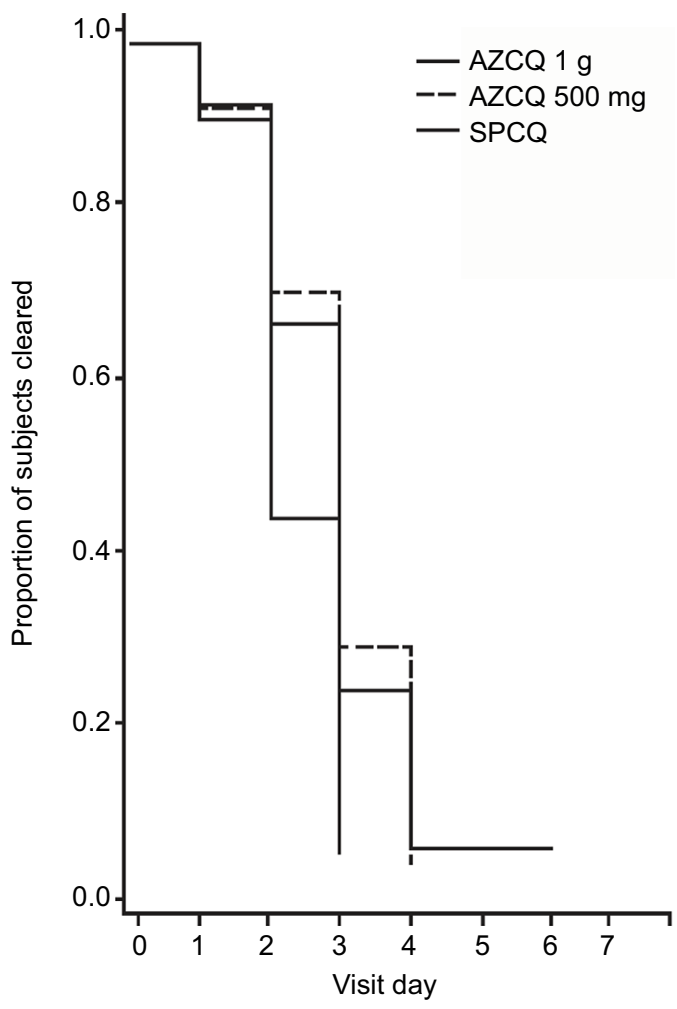

$p$-value $(A Z C Q 1 \mathrm{~g}$ vs. SPCQ $)=0.0003$ $p$-value (AZCQ $500 \mathrm{mg}$ vs. SPCQ) $=0.0001$ $p$-value (AZCQ $500 \mathrm{mg}$ vs. AZCQ $1 \mathrm{~g})=0.8894$

Figure 3 Asexual parasite clearance time in patients receiving AZCQ I g, AZCQ $500 \mathrm{mg}$, or SPCQ in study A066II 20 (India).

Abbreviations: AZCQ, azithromycin-chloroquine; SPCQ, chloroquine plus sulfadoxine-pyrimethamine.

Day 28 parasite clearance rates between $1 \mathrm{~g}$ azithromycin combination treatment $(83.6 \%)$ and $500 \mathrm{mg}$ azithromycin combination treatment (66.1\%; Table 3) was $17.5 \%$, and the $95 \% \mathrm{CI}$ for the difference was $-34.2 \%,-0.7 \%$. As a result of this observation, exploratory analyses were performed to determine the potential impact of patient body weight on the clearance rate of $P$. falciparum asexual parasites. In the $1 \mathrm{~g}$ AZCQ group, participants weighing $\geq 50 \mathrm{~kg}$ had a lower clearance rate $(\mathrm{n} / \mathrm{N}=41 / 53 ; 77.4 \%)$ than those weighing $<50 \mathrm{~kg}(\mathrm{n} / \mathrm{N}=27 / 30 ; 90.0 \%)$ in the parasitologically eligible population, and the clearance rates were $77.6 \%$ (38/49) and $95.8 \%$ (23/24) of patients, respectively, in the evaluable population. In addition, participants weighing $\geq 50 \mathrm{~kg}$ appeared to fail earlier in the $1 \mathrm{~g}$ AZCQ arm than participants weighing $<50 \mathrm{~kg}$. There was no significant relationship between weight and efficacy in the SPCQ arm.

Of all isolates collected, only 18 (7.8\%) were sensitive to CQ. Among resistant isolates, most were of the SVMNT haplotype (Table 5). Parasitologic response was observed in all study participants with CQ-sensitive isolates, whereas lower parasitologic response rates were seen in study par-

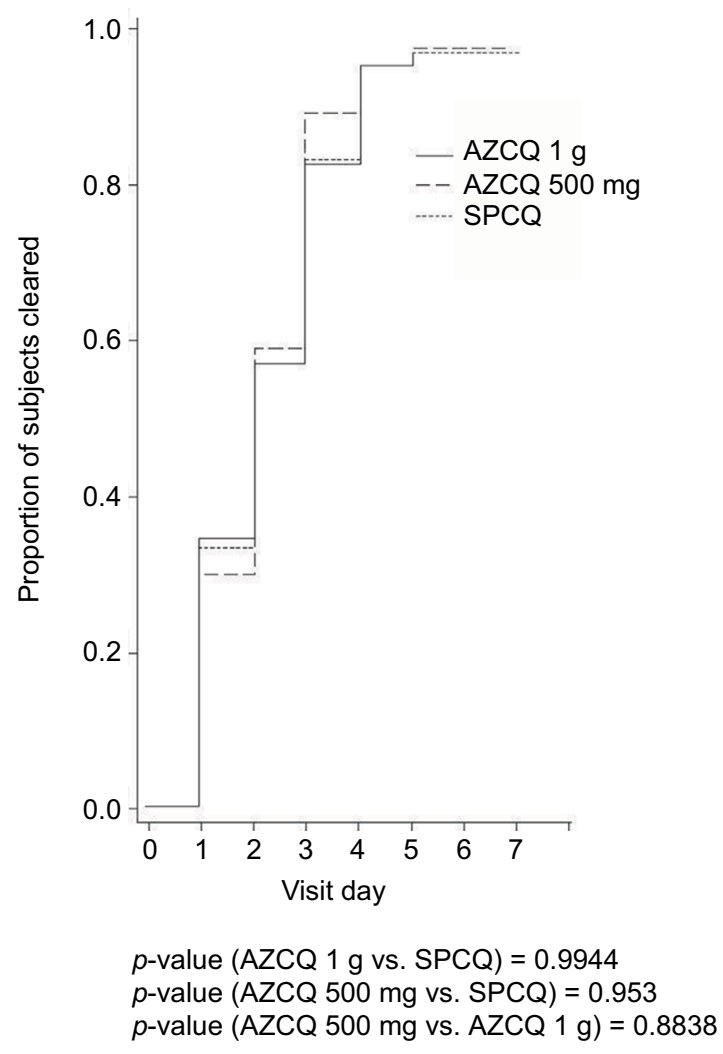

Figure 4 Fever clearance time in patients receiving AZCQ I g, AZCQ 500 mg, or SPCQ in study A066 I I 20 (India).

Abbreviations: AZCQ, azithromycin-chloroquine; SPCQ, chloroquine plus sulfadoxine-pyrimethamine.

ticipants with CQ-resistant isolates (78.7\% with SVMNT and $85.3 \%$ with CVIET).

Blood blots from subjects who failed to eradicate the $P$. falciparum parasite while on study drug were sent to the US NAMRU-2 for parasite MSP-2 genotyping. Paired samples from Day 1 and the day of failure for each subject were sent. Samples from only 31 subjects were received by NAMRU- 2 and analyzed.

\section{Colombia and Suriname comparative study (A066 I I26)}

Of the 14 patients randomized to AZCQ $500 \mathrm{mg}$ at the time of an early interim analysis, four of $11(36.4 \%)$ completers achieved parasite clearance at Day 28 . The initial recommendation from DSMB for the India study did not depend on cross-study pooling of data, with insufficient data regarding other geographic areas to recommend global discontinuation of the low-dose arm. A pooled review of the performance of the $500 \mathrm{mg}$ AZCQ arm from Colombia and Suriname led to the decision to subsequently close further enrollment to this arm due to the high failure rate. In the final analysis, asexual parasite clearance at Day 28 was lower for those patients receiving AZCQ $1 \mathrm{~g}$ compared 
Table 4 Gametocyte clearance in studies A066II 20 (India), A066I I 26 (Colombia/Suriname), and A066I I54 (Colombia/India)

\begin{tabular}{|c|c|c|c|c|c|}
\hline & \multicolumn{2}{|c|}{ India $\left(A 066\right.$ I I 20) ${ }^{a}$} & \multirow{2}{*}{$\frac{\text { Colombia/Suriname (A066 I I 26) }}{\text { AZCQ I g }}$} & \multicolumn{2}{|c|}{ Colombia/India (A066 I I 54) } \\
\hline & AZCQ I g & SPCQ & & AP & AZCQ $2 \mathrm{~g}$ \\
\hline Randomized, $\mathrm{n}$ & 83 & 780 & 113 & 116 & 110 \\
\hline Day 7, n (\%) & $63 / 73(86)$ & $52 / 104(50)$ & $52 / 104(50)$ & $63 / 115(55)$ & $92 / 109(84)$ \\
\hline Day I4, n (\%) & $59 / 70(84)$ & $52 / 104(50)$ & $51 / 104(49)$ & $56 / 113(50)$ & $89 / 109(82)$ \\
\hline Day 2I, n (\%) & $58 / 67(87)$ & $52 / 104(50)$ & $46 / 100(46)$ & $59 / 113(52)$ & $82 / 106(77)$ \\
\hline Day $28, \mathrm{n}(\%)$ & $55 / 61(90)$ & $52 / 104(50)$ & $38 / 89(43)$ & $60 / 110(55)$ & $80 / 105(76)$ \\
\hline Day 35, n (\%) & $48 / 54(89)$ & $52 / 104(50)$ & $38 / 87(44)$ & $61 / 111(55)$ & $79 / 103(77)$ \\
\hline Day 42, n (\%) & $50 / 57(88)$ & $52 / 104(50)$ & $38 / 85(45)$ & $60 / 109(55)$ & $80 / 104$ (77) \\
\hline
\end{tabular}

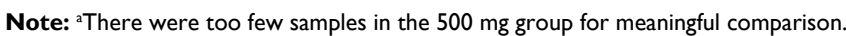

Abbreviations: AP, atovaquone-proguanil; AZCQ, azithromycin-chloroquine; SPCQ, chloroquine plus sulfadoxine-pyrimethamine.

Table 5 Clearance Rates by pfcrt mutation at baseline in study A0066I I 20 (India)

\begin{tabular}{|c|c|c|c|c|c|c|}
\hline & \multicolumn{2}{|c|}{ AZCQ I g $(n=83)$} & \multicolumn{2}{|c|}{ AZCQ $500 \mathrm{mg}(\mathrm{n}=67)$} & \multicolumn{2}{|c|}{ SPCQ $(n=80)$} \\
\hline & $n / \mathbf{N}$ & $\%$ of total & $\mathbf{n} / \mathbf{N}$ & $\%$ of total & $\mathbf{n} / \mathbf{N}$ & $\%$ of total \\
\hline CVMNK sensitive & $5 / 5(100 \%)$ & 6.0 & $6 / 6(100 \%)$ & 9.0 & $7 / 7(100 \%)$ & 8.8 \\
\hline $\mathrm{CQ}$ resistant & $64 / 75(85.3 \%)$ & 77.1 & $4 I / 59$ (69.5\%) & 61.2 & $63 / 69$ (91.3\%) & 78.8 \\
\hline SVMNT & $54 / 64(84.4 \%)$ & 65.1 & $33 / 49(67.3 \%)$ & 49.3 & $51 / 56(9 \mid .1 \%)$ & 63.8 \\
\hline CVIET & $10 / 11(90.9 \%)$ & 12.0 & $8 / 10(80.0 \%)$ & 11.9 & $12 / 13(92.3 \%)$ & 15.0 \\
\hline Negative & $2 / 2(100 \%)$ & 2.4 & I/I (100\%) & 1.5 & $\mathrm{I} / 2(50 \%)$ & 1.3 \\
\hline Others ${ }^{\mathrm{a}}$ & $\mathrm{I} / \mathrm{I}(100 \%)$ & 1.2 & 0/I (0\%) & 0.0 & $2 / 2(100 \%)$ & 2.5 \\
\hline
\end{tabular}

Notes: n, number of subjects cleared at Day 28; N, number of subjects with the respective mutations at baseline; CVIET, Southeast Asian/African origin; CVMNK, wild type; SVMNT, South American origin. ${ }^{a}$ Others included $P$. vivax or missing sample.

Abbreviations: AZCQ, azithromycin-chloroquine; CQ, chloroquine; P. vivax, Plasmodium vivax; SPCQ, chloroquine plus sulfadoxine-pyrimethamine.

with those receiving AP: 66/112 (58.9\%) versus 112/113 (99.1\%), difference (95\% CI), -42.0, (-52.2, -31.7; Table 3). Patients from Suriname receiving AZCQ $1 \mathrm{~g}$ were less likely to respond than those from Colombia: $9 / 36$

Table 6 Asexual parasite clearance by center at Day 28 in studies A066II 20 (India), A066II 26 (Colombia/Suriname), and A0066II 54 (Colombia/India)

\begin{tabular}{clll}
\hline & \multicolumn{3}{l}{ Cleared/evaluable (\%) } \\
\cline { 2 - 4 } & AZCQ I g & Comparator & $\begin{array}{l}\text { Difference, \% } \\
\text { (95\% CI) }\end{array}$ \\
\hline A066II20 & $61 / 73(84)$ & $68 / 72(94)$ & $-10.9(-22.6,0.8)$ \\
Mumbai & $11 / 14(79)$ & $13 / 14(93)$ & $-14.3(-47.8,19.2)$ \\
Bambolim (Goa) & $15 / 21(71)$ & $19 / 21(90)$ & $-19.0(-47.4,9.3)$ \\
Indore & $1 / 1(100)$ & $2 / 2(100)$ & \\
Nagpur & $3 / 3(100)$ & $1 / 1(100)$ & \\
Rourkela & $16 / 18(89)$ & $19 / 19(100)$ & $-11.1(-31.5,9.3)$ \\
Guwahati & $15 / 16(94)$ & $14 / 15(93)$ & $0.4 I(-24.0,24.8)$ \\
A066II26 & $66 / 112(59)$ & $112 / 113(99)$ & $-42.0(-52.2,-31.7)$ \\
Colombia & $55 / 76(72)$ & $78 / 79(99)$ & $-26.4(-38.1,-14.7)$ \\
$\quad$ Tumaco & $34 / 53(64)$ & $53 / 54(98)$ & $-34.0(-49.4,-18.6)$ \\
$\quad$ Tadó/Guapi & $21 / 23(91)$ & $25 / 25(100)$ & NA \\
Suriname & & & \\
$\quad$ Paramaribo & $9 / 36(25)$ & $34 / 34(100)$ & $-75.0(-92.2,-57.8)$ \\
A066II54 & AZCQ 2 g & $90 \%$ Cl & \\
Colombia (Tumaco) & $53 / 55(96.4)$ & $(91.3,100)$ & \\
India (Goa) & $51 / 55(98.1)$ & $(94.0,100)$ & \\
\hline
\end{tabular}

Note: Values are $n$ unless otherwise noted.

Abbreviations: $\mathrm{AZCQ}$, azithromycin-chloroquine; $\mathrm{Cl}$, confidence interval; $\mathrm{NA}$, not applicable.
(25\%) versus 55/76 (72\%), respectively (Table 6). Among the failures on AZCQ $1 \mathrm{~g}$, LTF was more common than ETF (37/49 vs. 12/49; Table 3).

Asexual parasite clearance occurred earlier in the AP treatment group compared with the AZCQ $500 \mathrm{mg}$ and the AZCQ $1 \mathrm{~g}$ treatment groups ( $p=0.09$, AZCQ $1 \mathrm{~g}$ vs. AP; Figure 5).

Fever cleared in the majority of the subjects by Day 3 in AZCQ $1 \mathrm{~g}$ and AP treatment groups. There was no significant difference in the time to fever clearance between the $1 \mathrm{~g} \mathrm{AZCQ}$ arm and the AP arm (Figure 6). However, when evaluating country-level data, a significant difference in fever clearance between $1 \mathrm{~g}$ AZCQ and AP treatment groups was observed in Suriname ( $p=0.025)$, but no significant difference was noted in Colombia.

Owing to early discontinuation of the $500 \mathrm{mg}$ AZCQ treatment group, a dose-response relationship between the AZCQ treatment groups was not assessed. However, comparison of parasite clearance rates was made between participants weighing $\leq 50 \mathrm{~kg}$ and $\geq 50 \mathrm{~kg}$ in the $1 \mathrm{~g}$ AZCQ group. The number of participants in the $\leq 50 \mathrm{~kg}$ subgroup was small in all study arms. Overall, in participants weighing $\leq 50 \mathrm{~kg}$ who received $1 \mathrm{~g}$ AZCQ treatment, asexual parasite clearance rate was $64 \%$, whereas in participants weighing $\geq 50 \mathrm{~kg}$, the clearance rate was $56 \%$. This difference was not observed in Suriname but was observed in Colombia. 

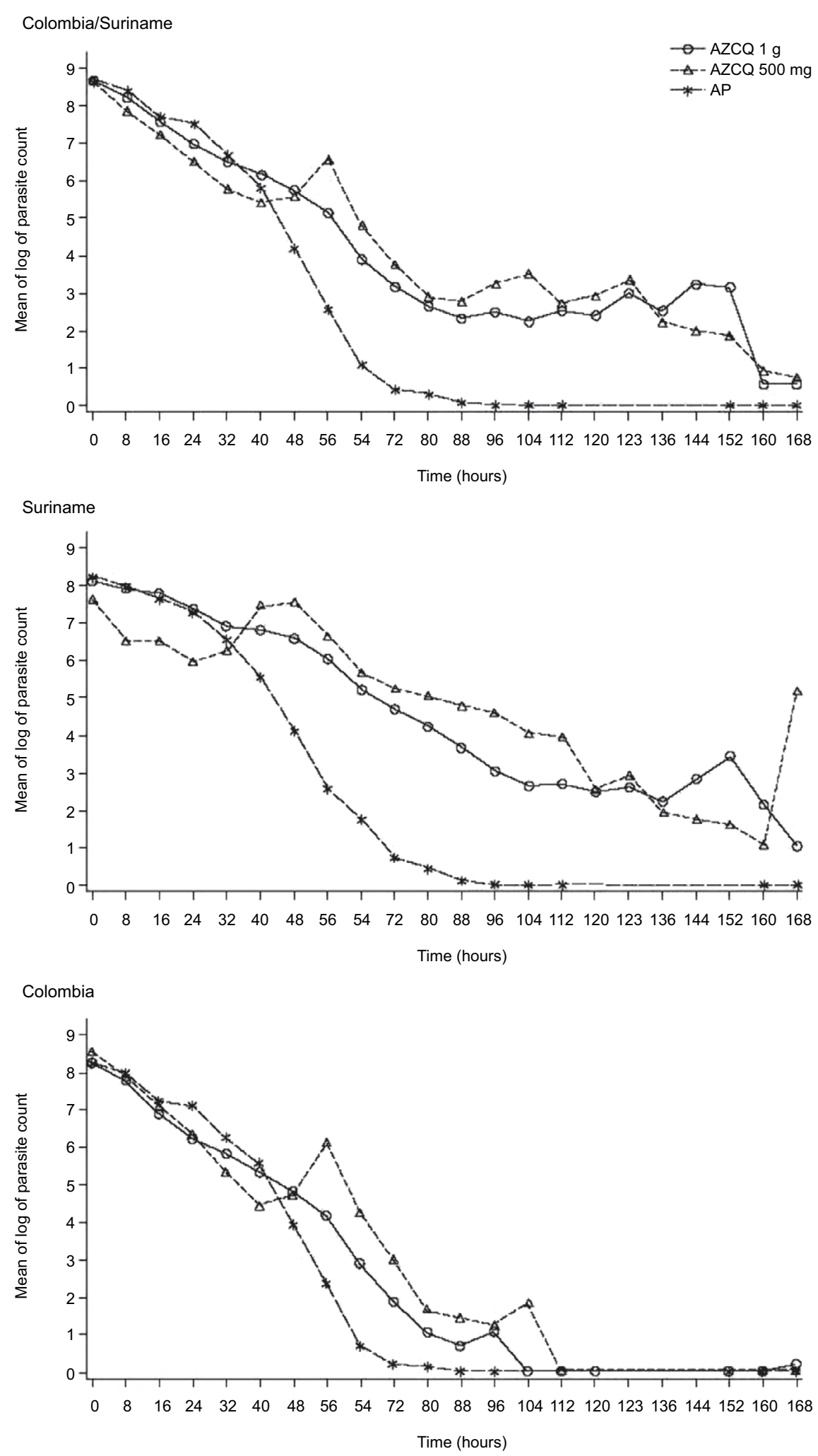

Figure 5 Parasite reduction in patients receiving AZCQ I g, AZCQ 500 mg, or AP in study A066I I 26 (Colombia/Suriname). Abbreviations: AP, atovaquone-proguanil; $A Z C Q$, azithromycin-chloroquine. 


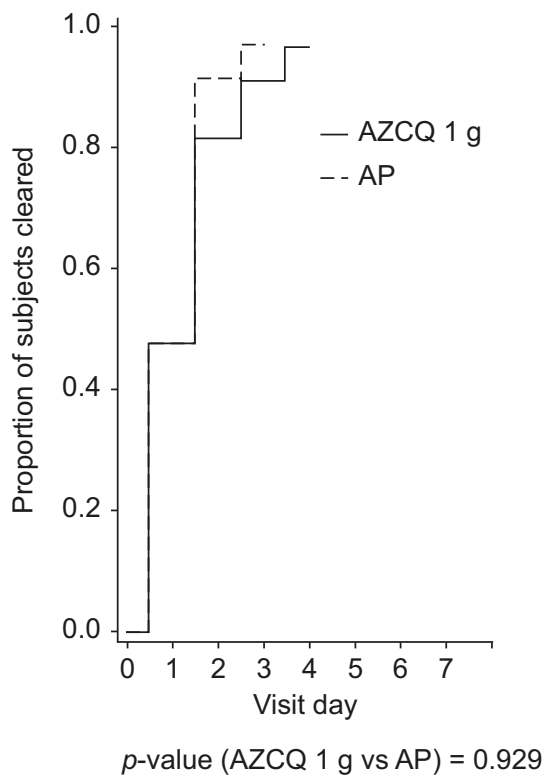

Figure 6 Fever clearance time in patients receiving AZCQ I g or AP in study A066II 26 (Colombia/Suriname).

Abbreviations: AP, atovaquone-proguanil; AZCQ, azithromycin-chloroquine.

Subject weight had no apparent effect on clearance rates in subjects treated with AP.

Almost all (98.4\%) P. falciparum isolates recovered from patients in Colombia and Suriname carried CQ-resistance alleles, in particular the SVMNT $(63.2 \%)$ or CVMET (36.8\%) resistance haplotype (Table 7). All isolates from Suriname carried the SVMNT haplotype.

Of the 43 subjects analyzed, 37 subjects were considered as recrudescent (treatment failures), and five subjects had reinfections with a new strain of $P$. falciparum, while one subject was not a treatment failure (as per project database) and samples should not have been sent for analysis.

\section{Non-comparative Colombia/India study (A066 I I54)} In all, 110 patients received AZCQ $2 \mathrm{~g}$, divided between one center in Tumaco, Colombia, and one center in Goa, India. These centers were chosen based on the lower than average parasite clearance rates that were observed for patients given AZCQ $1 \mathrm{~g}$ (Table 3) in previous studies (A0661120 and A0661126). The demographic and baseline characteristics of these patients were similar to those of the prior randomized trials, with patients in Goa being generally young men, whereas there were similar numbers of male and female patients in Tumaco (Table 1). The majority of subjects in Goa and Tumaco had no prior history of malaria.

At Day 28, the PCR-corrected parasite clearance rate was 96.4\% (53/55) in Tumaco and 98.1\% (51/52) in Goa, with an overall Day 28 response rate of 97.2\% (104/107; Table 3). The overall response rate at Day 42 was 96.3\% (103/107).

The asexual parasite clearance rate (PCR corrected) on Days 7 and 14 was $100 \%$, with a slight decrease beginning at Day 21 (98.08\% in Goa and 100\% in Tumaco) and continuing to the last assessment on Day 42 (98.08\% in Goa and $94.55 \%$ in Tumaco).

Analysis of parasite clearance rates (PCR corrected) on Day 28 (parasitologically evaluable population), based on baseline body weight, showed that the parasite clearance rates were comparable between the two subgroups (72 of 74 [97.3\%] patients $\geq 50 \mathrm{~kg}$ and 32 of 33 [97.0\%] patients $\leq 50 \mathrm{~kg}$ ).

The proportion of patients with clearance of gametocytes on Day 7 was $84 \%(n / N=92 / 109)$ and declined thereafter to $77 \%$ (n/N = 80/104) on Day 42 (Table 4$)$. The majority of subjects had no fever by Day 3 (Figure 7). There were three LTFs (Table $3)$, two of which were associated with clinical symptoms.

Overall, 41.8\% ( $/ \mathrm{N}=46 / 110)$ of patients carried parasites with the SVMNT haplotype at baseline, $32.7 \%$ ( $\mathrm{n} / \mathrm{N}=36 / 110)$ carried parasites with the CVMNT haplotype, $15.5 \%(\mathrm{n} / \mathrm{N}=17 / 110)$ carried parasites with the CVMET haplotype at baseline, $4.6 \%(\mathrm{n} / \mathrm{N}=5 / 110)$ carried parasites with the CVIET haplotype, and $0.9 \%(\mathrm{n} / \mathrm{N}=1 / 110)$ of patients carried parasites with a mixed haplotype at baseline.

Of the six subjects with recurrent parasitemia who were tested with parasite genotyping, two subjects had reinfection

Table 7 Clearance rates by pfort mutation at baseline in study A066 I 26 (Colombia/Suriname)

\begin{tabular}{|c|c|c|c|}
\hline \multirow[t]{2}{*}{ pfcrt mutation at baseline } & AZCQ I g $(n=1 \mid 4)$ & AZCQ $500 \mathrm{mg}(\mathrm{n}=14)$ & $\operatorname{AP}(n=116)$ \\
\hline & n/N (\%) & n/N (\%) & n/N (\%) \\
\hline CQ sensitive & $0 / /(0)$ & $3 / 3(100)$ & - \\
\hline CVMNK & $0 / /(0)$ & $3 / 3(100)$ & - \\
\hline $\mathrm{CQ}$ resistant & $67 / 101(66)$ & $3 / 7(43)$ & $104 / 104(100)$ \\
\hline CVMET & $38 / 38(100)$ & $2 / 2(100)$ & $38 / 38(100)$ \\
\hline SVMNT & $29 / 63(46)$ & $\mathrm{I} / 5(20)$ & $66 / 66(100)$ \\
\hline Negative & - & - & $\mathrm{I} / \mathrm{I}(100)$ \\
\hline Others $^{\mathrm{a}}$ & $8 / 8(100)$ & $4 / 4(100)$ & $6 / 6(100)$ \\
\hline
\end{tabular}

Notes: n, number of subjects cleared at Day 28; N, number of subjects with the respective mutations at baseline; CVMET, South American origin; CVMNK, wild type; SVMNT, South American origin. ${ }^{a}$ Others included $P$. vivax or missing sample.

Abbreviations: AP, atovaquone-proguanil; AZCQ, azithromycin-chloroquine; $\mathrm{CQ}$, chloroquine; P. falciparum, Plasmodium falciparum; pfcrt, $P$. falciparum chloroquine resistance transporter gene; $P$. vivax, Plasmodium vivax. 


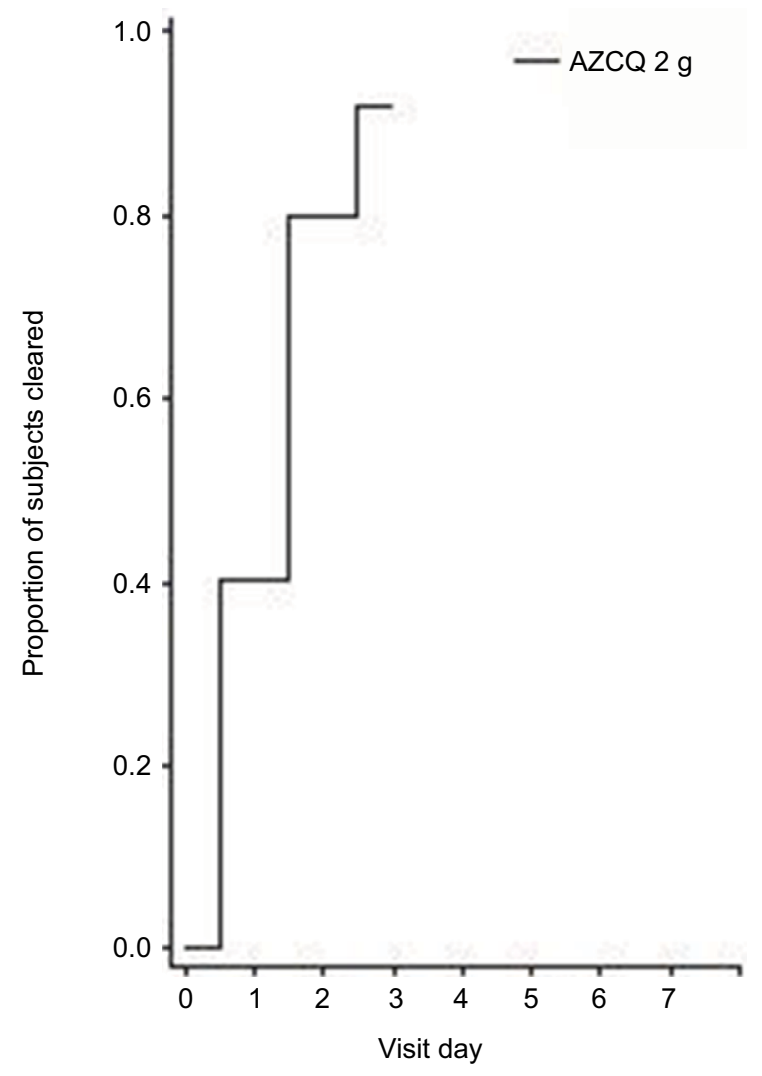

Figure 7 Fever clearance time in patients receiving AZCQ $2 \mathrm{~g}$ in study A066 II 54 (Colombia/India).

Abbreviation: AZCQ, azithromycin-chloroquine.

(new infection) of P. falciparum with a new genotype, three subjects were considered recrudescent (true treatment failures), and for one subject, days of failure blood blots were not available for testing and outcome could not be determined.

\section{Safety}

AEs occurring at a rate of $>2 \%$ in any regimen from studies A0661120, A0661126, or A0661154 are provided in Table 8. AEs most commonly observed in the AZCQ treatment groups were dose-related gastrointestinal events, including nausea, vomiting, and diarrhea, that are known side effects of azithromycin. In addition, pruritus was commonly observed almost exclusively among patients with pigmented skin. In the Indian comparative study (A0661120), discontinuations due to AEs occurred in 3/83 (3.6\%) of patients in the AZCQ $1 \mathrm{~g}$ treatment group and $1 / 80(1.3 \%)$ of patients in the AP treatment group; no discontinuation for AEs occurred in the AZCQ $500 \mathrm{mg}$ or $2 \mathrm{~g}$ treatment groups. There were 14 serious AEs in 13 patients (five in the AZCQ $1 \mathrm{~g}$ group, five in the AZCQ $500 \mathrm{mg}$ group, and three in the SPCQ group). All events except one were considered to be unrelated to treatment. One patient in the SPCQ group experienced abnormal behavior 2 days posttherapy, which was attributed by the investigator to CQ. In the Colombia and Suriname comparative study (A0661126), discontinuations due to AEs occurred in 6/114 (5.2\%) of patients in the AZCQ $1 \mathrm{~g}$ treatment group and $1 / 16(0.9 \%)$ of patients in the AP treatment group; no discontinuation for AEs occurred in the AZCQ $500 \mathrm{mg}$ group. There were 10 serious AEs in nine patients (three in the AZCQ $1 \mathrm{~g}$ group, one in the AZCQ $500 \mathrm{mg}$ group, and five in the AP group). None of these were considered by investigators to be treatment related, and four of these events occurred posttherapy. There were no serious AEs reported in the non-comparative study (A0661154). In the clinical trial in India (A0661120), patients with the following known blood dyscrasias were excluded: megaloblastic anemia, agranulocytosis, aplastic anemia, thrombocytopenia, leukopenia, neutropenia, and hemolytic anemia. Specific thresholds for hemoglobin were not established. All treatment groups were similar in incidence of concurrent medical history of anemia at the time of study entry $(11,10$, and 10 subjects in the AZCQ 1,000 $\mathrm{mg}$, AZCQ $500 \mathrm{mg}$, and SPCQ treatment groups, respectively). Anemia was reported as an AE in two subjects (3\%) in the AZCQ $500 \mathrm{mg}$ treatment group and in three subjects (3.8\%) in the SPCQ treatment group. Investigators did not consider these events to be related to investigational product. There were no clinically significant median changes from baseline to last observation in any laboratory value, and no subject discontinued from the study due to abnormal laboratory values. All treatment groups were similar in incidence of subjects with decreased hemoglobin (10, 9, and 10 subjects in the AZCQ 1,000 mg, AZCQ $500 \mathrm{mg}$, and SPCQ treatment groups, respectively). One subject in the AZCQ $500 \mathrm{mg}$ treatment group experienced moderate anemia from Days 3 to 21 . Hemoglobin was $4.7-13.5 \mathrm{~g} / \mathrm{dL}$ (baseline $4.8 \mathrm{~g} / \mathrm{dL}$ ). The subject received a transfusion due to the anemia.

\section{Discussion}

From these data collected in three clinical trials, three conclusions can be drawn. First, $500 \mathrm{mg}$ AZCQ was inadequate for the clearance of $P$. falciparum as shown by the Day 28 parasite clearance dose response and the low efficacy rates and subsequent discontinuation of the $500 \mathrm{mg}$ treatment groups in studies A0661120 and A0661126. Second, the efficacy of the AZCQ combination using doses of azithromycin of $500 \mathrm{mg}$ and 1,000 $\mathrm{mg}$ varied with geographic region. Day 28 parasite clearance rates for $500 \mathrm{mg}$ and $1 \mathrm{~g}$ AZCQ were $66.1 \%$ (500 mg) and 84\% (1,000 mg) in India and $36.4 \%(500 \mathrm{mg})$ and 59\% (1,000 mg) in Latin America. 
Third, a dose of $2 \mathrm{~g}$ AZCQ in Tumaco (Colombia) and Goa (India) achieved highly efficacious clinical response rates. The Day 28 parasite clearance rate for 2,000 mg AZCQ in study A0661154 was $97.2 \%$ overall with rates of $96.4 \%$ and $98.1 \%$ in Tumaco and Goa, respectively. This increased efficacy, relative to that observed in studies A0661120 and A0661126, could be explained by the higher dose of azithromycin. This explanation is supported by the higher efficacy rates observed in those studies for subjects receiving 1,000 mg AZCQ when compared with subjects receiving $500 \mathrm{mg}$ AZCQ. It is further supported by the higher efficacy rate observed in subjects who received a higher milligram per kilogram dose of azithromycin in those studies due to differences in body weight.

These trials were designed to investigate the efficacy of the addition of azithromycin to CQ for the treatment of $P$. falciparum malaria in India, Colombia, and Suriname and demonstrated an exposure-adjusted response to treatment as well as response to treatment in a subset of patients with CQresistant organisms at baseline. The responses at the initial doses chosen (500 mg azithromycin plus $600 \mathrm{mg}$ CQ base and $1 \mathrm{~g}$ azithromycin plus $600 \mathrm{mg}$ CQ base), however, did not result in determining a regimen that would support larger confirmatory studies in these countries. These dose-finding observations, however, did identify a dose of azithromycin ( $2 \mathrm{~g}$ ) that, when added to CQ, achieved parasite clearance rates that were considered highly effective.

Following the observation of a dose-response relationship between the $1 \mathrm{~g}$ and $500 \mathrm{mg}$ azithromycin combination groups in the Indian study (A0661120), exploratory analyses were performed evaluating the impact of weight on parasite clearance rates. A relationship between weight and response was seen in the $1 \mathrm{~g}$ AZCQ group in this study and, to a lesser extent, in the Colombia/Suriname study (A0661126). Analyses of clearance rates at Day 28 according to subject weight $(<50 \mathrm{~kg}$ and $\geq 50 \mathrm{~kg}$ ) were performed in study A0661120 (India). In the 1,000 $\mathrm{mg}$ AZCQ treatment group, the group of subjects weighing $\geq 50 \mathrm{~kg}$ had a lower clearance rate than those weighing $<50 \mathrm{~kg}, 27 / 30(90.0 \%)$ and $41 / 53(77.4 \%)$ subjects in the $<50 \mathrm{~kg}$ and $\geq 50 \mathrm{~kg}$ subgroups, respectively, in the parasitologically eligible population and 23/24 (95.8\%) and 38/49 $(77.6 \%)$ subjects, respectively, in the evaluable population. The estimated ratio of the odds of clearance was 1.116 times for each unit increase in milligram per kilogram (95\% CI: 1.028, 1.212, $p=0.0088$ ). In study A0661126 in Suriname, the weight of subjects did not appear to have an effect on clearance in subjects treated with $1,000 \mathrm{mg}$ AZCQ, while in Colombia, clearance rates of $85.7 \%$ and $71.0 \%$ were observed in the $\leq 50 \mathrm{~kg}$ and $>50 \mathrm{~kg}$ subgroups of 1,000 mg AZCQ-treated subjects, respectively. Thus, study A0661154 investigating $2 \mathrm{~g}$ AZCQ was conducted in Goa, India, and Tumaco in Colombia, where this dose response was significant in the previous studies. However, parasite clearance rates in study A0661154 of $2 \mathrm{~g} \mathrm{AZCQ}$ were comparable between weight subgroups, exceeding $95 \%$ for participants who weighed $\leq 50 \mathrm{~kg}$ and $>50 \mathrm{~kg}$. A dose-response was not observed in either comparator group (SPQC or AP) in the comparator studies. These findings suggest that patient body weight (i.e., milligram per kilogram dose of azithromycin) may impact parasite clearance, making this parameter an important consideration in dose selection for azithromycin combination treatments within a certain dose range.

Table 8 Treatment-related AEs in >2\% of patients in any treatment group in studies A066 I I 20 (India), A066 I I 26 (Colombia/Suriname), and A066II 54 (Colombia/India)

\begin{tabular}{|c|c|c|c|c|c|}
\hline & AZCQ $2 \mathrm{~g}(\mathrm{n}=1 \mid 0)$ & AZCQ I g $(n=197)$ & AZCQ $500 \mathrm{mg}(\mathrm{n}=8 \mathrm{I})$ & $\operatorname{SPCQ}(n=80)$ & $\operatorname{AP}(n=116)$ \\
\hline & \multicolumn{5}{|l|}{ n (\%) of patients } \\
\hline Any AE & $48(44)$ & $52(26)$ & $8(10)$ & $4(5)$ & $14(12)$ \\
\hline Pruritus & $4(4)$ & $30^{\mathrm{a}}(15)$ & $5(6)$ & 0 & $2(2)$ \\
\hline Diarrhea & $13(12)$ & $7(4)$ & 0 & 0 & $4(3)$ \\
\hline Paresthesia & 0 & $6(3)$ & 0 & 0 & 0 \\
\hline Abdominal pain & 0 & $5(3)$ & 0 & 0 & $4(3)$ \\
\hline Headache & 0 & $3(2)$ & 0 & 0 & $I(I)$ \\
\hline Gastritis & $4(4)$ & $4(2)$ & $I(I)$ & 0 & 0 \\
\hline Vomiting ${ }^{\mathrm{b}}$ & $20(18)$ & $7(4)$ & $I(I)$ & $3(4)$ & $I(I)$ \\
\hline Nausea & $33(30)$ & 0 & 0 & 0 & 0 \\
\hline Dehydration & $4(4)$ & 0 & 0 & 0 & 0 \\
\hline
\end{tabular}

Notes: ${ }^{2} 28 / 30$ patients with pruritus from Colombia/Suriname. ${ }^{b}$ One patient on AZCQ $2 \mathrm{~g}$ complained of severe vomiting.

Abbreviations: $\mathrm{AE}$, adverse event; $\mathrm{AP}$, atovaquone-proguanil; $\mathrm{AZCQ}$, azithromycin-chloroquine; SPCQ, chloroquine plus sulfadoxine-pyrimethamine. 
The lower Day 28 parasitologic clearance rate in Suriname (25\%) versus Colombia (72\%) and India (83.6\%) observed in the comparative studies was especially striking. Isolates from the Amazon basin have historically been less responsive to treatment than isolates from other regions. Data from the Peruvian Amazon in the late 1990s suggested that new strains of P. falciparum had been introduced, and some considerable variability was observed in the $\mathrm{IC}_{50}$ values for CQ among the isolates tested. ${ }^{43}$

In a previous study conducted between 1998 and 2001, in study sites in India characterized as stable malaria transmission areas with RI resistance approaching 70\% (Gujarat, Delhi, Madhya Pradesh, Orissa, and Assam), baseline mean parasites per microliter of blood in the AZCQ treatment group was $6,417 .{ }^{16}$ In $56(88 \%)$ of the 64 subjects in the AZCQ treatment group, resolution of fever and parasitemia occurred by Day 3, and in 61 (97\%) of 63 participants, it occurred by Day 7 . Through Day 28, no participant had a recrudescence of infection. The median time to resolution of parasitemia was 36 hours. In study A0661120, a regional difference was observed in asexual parasite clearance rates with two of the sites located on the Western coast of India having lower clearance rates with azithromycin combination treatment than the other four sites. Sites 1002 (Mumbai) and 1005 (Goa) experienced lower clearance rates overall (78.57\% and $71.42 \%$, respectively) as compared with sites 1001 (Guwahati), 1003 (Rourkela), 1007 (Nagpur), and 1008 (Indore) with clearance rates of $88.88 \%-100 \%$. The numbers of subjects treated with AZCQ $1,000 \mathrm{mg}$ or SPCQ at Sites 1007 and 1008 were small (four and five subjects, respectively), so these data must be viewed with caution.

The AEs associated with azithromycin were dose proportional. Although no discontinuations for AEs were observed on the $2 \mathrm{~g}$ dose, the gastrointestinal AE rate approached the limits of tolerability. Study of the newer formulation of azithromycin designed to minimize these gastrointestinal AEs, combined with CQ, may be warranted. ${ }^{44}$

These trials have certain limitations. While the success rates for the AZCQ $2 \mathrm{~g}$ regimen were encouraging, further work comparing against established regimens would need to be performed to establish the relative safety and efficacy of this regimen.

\section{Conclusion}

In summary, azithromycin given in combination with CQ at doses of $500 \mathrm{mg}$ and $1 \mathrm{~g}$ for $P$. falciparum malaria in India, Colombia, and Suriname failed to achieve non-inferiority relative to established comparator agents, AP. However, based on a dose-response identified in these studies and supported by subsequent results, a $2 \mathrm{~g}$ dose of azithromycin given with CQ may be an efficacious regimen in India and Colombia.

\section{Acknowledgments}

Determination of markers for CQ resistance and third party review of malaria smears were performed by Dr. Kevin Kain's laboratory at the Center for Travel and Tropical Medicine at Toronto General Hospital, Toronto, ON, Canada. Medical writing and editorial support were provided by Aruna Seth, $\mathrm{PhD}$, and Sharmila Blows, $\mathrm{PhD}$, of Engage Scientific Solutions and was funded by Pfizer. These studies were funded by Pfizer and Medicines for Malaria Venture. The authors gratefully acknowledge the other investigators involved in this study: India (A0661120): Prabhash Bhattacharyya, Dr. Paramesh Bharali, Dipti Sarma, Dr. Vas Dev, Rupjyoti Talukdar, Dr. Sudeshna Sunil Dalvi, Sanish Davis, Dr. Sanath Hegde, Dr. Ganesh S. Kulkarni, Dr. Sanjay Mehta, Dr. Balaji Dagadu More, Dr. Manmath Nivrutti Patekar, Saroj Mishra, Sanjay Kumar Acharya, Dr. Sanjib Mohanty, Dr. Rajyabardhan Pattnaik, Dr. Surya Kant Sharma, Prajesh Kumar Tyagi, Nagesh Dubhashi, Dr. Manjunath Desai, Dr. Mahendra A. Kare, Dr. Anar V. Khandeparkar, Rajesh Gosavi, Dr. Chandrashekhar Atkar, Dr. Vishrant Mahadev Bharti, Dr. Sachin Jibhakate, Dr. Tejas Pandrang Veer Mukund Dattatray Ashtaputre, Mr. Manish N. Tardeja, Dr. Gajendra Bhandari, Dr. Pradeep Mehta, and Dr. Harshendra Shah. Colombia (A0661126): Dr. Jose Gabriel Carrasquilla, Shirley Vidal Castro, Dr. David Alexander Montilla Coral, Leda Romero Cuero, Aura Ligia Achury Esterilla, Ivan Fernando Quintero Fajardo, Dr. Jose Rodrigo Montoya Hernandez, Tulio Badin Murillo Mena, Manuel Fernando, Bautista Morales, Guelmis Capella Niebles, Robinson Pacheco, Alexandra Porras Ramirez, and Luis Gover Diuza Sanchez. Suriname (A0661126): J. Kevin Baird, Elisabeth Dams, Truus Derks, Ben Hewitt, Carmen Lucas, Dayanand Panchoe, Marja van Eer, and Stephen G.S. Vreden. AZCQ 2 g study (A0661154): Dr. Sandra Patricia Jurado, Nagesh Dubashi, Avinash N. Dubhashi, Narvenkar Kedareshwar, Anar Viraj Khandeparkar, and Ramnath Neurekar.

\section{Author contribution}

All authors contributed toward data analysis, drafting and critically revising the paper and agree to be accountable for all aspects of the work.

\section{Disclosure}

NG, NAK, DM, AS, and GU were investigators in these studies, sponsored by Pfizer. PV is a full-time employee of 
Pfizer. SS was an employee of Pfizer during the conduct of this study and is an employee of Sciformix, which was a paid consultant to Pfizer in connection with the development of this manuscript. The authors report no other conflicts of interest in this work.

\section{References}

1. World Health Organization. Guidelines for the Treatment of Malaria. 2015. Available from: http://apps.who.int/iris/bitstr eam/10665/162441/1/9789241549127_eng.pdf. Accessed February 11, 2017.

2. Myint HY, Tipmanee P, Nosten F, et al. A systematic overview of published antimalarial drug trials. Trans $R$ Soc Trop Med Hyg. 2004;98(2):73-81.

3. Nosten F, McGready R, d'Alessandro U, et al. Antimalarial drugs in pregnancy: a review. Curr Drug Saf. 2006;1(1):1-15.

4. Egan TJ, Kaschula CH. Strategies to reverse drug resistance in malaria. Curr Opin Infect Dis. 2007;20(6):598-604.

5. de Vries PI, Le NH, Le TD, et al. Short course of azithromycin/artesunate against falciparum malaria: no full protection against recrudescence. Trop Med Int Health. 1999;4(5):407-408.

6. Krudsood S, Silachamroon U, Wilairatana P, et al. A randomized clinical trial of combinations of artesunate and azithromycin for treatment of uncomplicated Plasmodium falciparum malaria in Thailand. Southeast Asian J Trop Med Public Health. 2000;31(4):801-807.

7. Na-Bangchang K, Kanda T, Tipawangso P, et al. Activity of artemetherazithromycin versus artemether-doxycycline in the treatment of multiple drug resistant falciparum malaria. Southeast Asian J Trop Med Public Health. 1996;27(3):522-525.

8. Eastman RT, Fidock DA. Artemisinin-based combination therapies: a vital tool in efforts to eliminate malaria. Nat Rev Microbiol. 2009;7(12):864-874.

9. Wongsrichanalai C, Pickard AL, Wernsdorfer WH, Meshnick SR. Epidemiology of drug-resistant malaria. Lancet Infect Dis. 2002;2(4):209-218.

10. Juliano JJ, Kwiek JJ, Cappell K, Mwapasa V, Meshnick SR. Minorityvariant pfcrt K76T mutations and chloroquine resistance, Malawi. Emerg Infect Dis. 2007;13(6):872-877.

11. Laufer MK, Thesing PC, Eddington ND, et al. Return of chloroquine antimalarial efficacy in Malawi. N Engl J Med. 2006;355(19):1959-1966.

12. Mwai L, Ochong E, Abdirahman A, et al. Chloroquine resistance before and after its withdrawal in Kenya. Malar J. 2009;8:106.

13. Pereira MR, Henrich PP, Sidhu AB, et al. In vivo and in vitro antimalarial properties of azithromycin-chloroquine combinations that include the resistance reversal agent amlodipine. Antimicrob Agents Chemother. 2011;55(7):3115-3124.

14. Panpanich R, Lerttrakarnnon P, Laopaiboon M. Azithromycin for acute lower respiratory tract infections. Cochrane Database Syst Rev. 2008;1:CD001954.

15. van Eijk AM, Terlouw DJ. Azithromycin for treating uncomplicated malaria. Cochrane Database Syst Rev. 2011;2:CD006688.

16. Dunne MW, Singh N, Shukla M, et al. A multicenter study of azithromycin, alone and in combination with chloroquine, for the treatment of acute uncomplicated Plasmodium falciparum malaria in India. J Infect Dis. 2005;191(10):1582-1588.

17. Nakornchai S, Konthiang P. Activity of azithromycin or erythromycin in combination with antimalarial drugs against multidrug-resistant Plasmodium falciparum in vitro. Acta Trop. 2006;100(3):185-191.

18. Noedl H, Wernsdorfer WH, Krudsood S, et al. Antimalarial activity of azithromycin, artemisinin and dihydroartemisinin in fresh isolates of Plasmodium falciparum in Thailand. Acta Trop. 2001;80(1):39-44.

19. Gingras BA, Jensen JB. Activity of azithromycin (CP-62,993) and erythromycin against chloroquine-sensitive and chloroquine-resistant strains of Plasmodium falciparum in vitro. Am JTrop Med Hyg. 1992;47(3):378-382.
20. Yeo AE, Rieckmann KH. Increased antimalarial activity of azithromycin during prolonged exposure of Plasmodium falciparum in vitro. Int $J$ Parasitol. 1995;25(4):531-532.

21. Biswas S. In-vitro antimalarial activity of azithromycin against chloroquine sensitive and chloroquine resistant Plasmodium falciparum. $J$ Postgrad Med. 2001;47(4):240-243.

22. Ohrt C, Willingmyre GD, Lee P, Knirsch C, Milhous W. Assessment of azithromycin in combination with other antimalarial drugs against Plasmodium falciparum in vitro. Antimicrob Agents Chemother. 2002;46(8):2518-2524.

23. Gingras BA, Jensen JB. Antimalarial activity of azithromycin and erythromycin against Plasmodium berghei. Am J Trop Med Hyg. 1993;49(1):101-105.

24. Andersen SL, Ager A, McGreevy P, et al. Activity of azithromycin as a blood schizonticide against rodent and human plasmodia in vivo. Am J Trop Med Hyg. 1995;52(2):159-161.

25. White NJ. In: Cook GC, Zumla AI, editors. Manson's Tropical Diseases. USA: Elsevier; 2009:1201-1300.

26. [webpage on the Internet]. Peru: Country Health Profile. Available from: http://www.paho.org/English/SHA/prflPER.htm. Accessed March 22, 2017.

27. Aramburu Guarda J, Ramal Asayag C, Witzig R. Malaria reemergence in the Peruvian Amazon region. Emerg Infect Dis. 1999;5(2): 209-215.

28. [webpage on the Internet]. The Roll-Back Malaria Initiative in the Rainforest Region of South America. Available from: http://www.paho. org/English/AD/DPC/CD/cartagena.htm. Accessed March 22, 2017.

29. [webpage on the Internet]. Malaria Incidence Estimates at Country Level for the Year 2004. 2017. Available from: http://www.who.int/malaria/ publications/atoz/incidence_estimations2/en/. Accessed 7 June 2017.

30. Loiola CCP, da Silva CJ, Tauil PL. Malaria control in Brazil: 1965 to 2001. Rev Panam Salud Publica. 2002;11(4):235-244.

31. de Souza JM. Epidemiological distribution of Plasmodium falciparum drug resistance in Brazil and its relevance to the treatment and control of malaria. Mem Inst Oswaldo Cruz. 1992;87(suppl 3):343-348.

32. Palacios FS. Analysis of the principal problems impeding normal development of malaria eradication programs. Bull Pan Am Health Organ. 1975;9(4):283-294.

33. Pan American Health Organization. 44th Directing Council. Status Report on Malaria Programs in the Americas (Based on 2002 Data). CD44/INF/3 (Eng.). September 17, 2003. Available from: http://www1. paho.org/english/gov/cd/cd44-inf3-e.pdf. Accessed March 22, 2017.

34. Kremsner PG, Looareesuwan S, Chulay JD. Atovaquone and proguanil hydrochloride for treatment of malaria. J Travel Med. 1999;6(suppl 1): S18-S20.

35. Srinivas. Malaria in India. 2015. Available from: http://www.malariasite. com/malaria-india/. Accessed February 2017.

36. Gogtay NJ, Desai S, Kadam VS, Kamtekar KD, Dalvi SS, Kshirsagar NA. A randomized, parallel-group study in Mumbai (Bombay), comparing chloroquine with chloroquine plus sulfadoxine-pyrimethamine in the treatment of adults with acute, uncomplicated, Plasmodium falciparum malaria. Ann Trop Med Parasitol. 2000;94(4):309-312.

37. Sagara I, Oduro AR, Mulenga M, et al. Efficacy and safety of a combination of azithromycin and chloroquine for the treatment of uncomplicated Plasmodium falciparum malaria in two multi-country randomised clinical trials in African adults. Malar J. 2014;13:458.

38. World Health Organization. Severe and complicated malaria. Trans $R$ Soc Trop Med Hyg. 1990;84(suppl 2):1-65.

39. [webpage on the Internet]. BinaxNOW® Malaria. Available from: http://www.alere.com/en/home/product-details/binaxnow-malaria.html. Accessed March 22, 2017.

40. Tietz NW. Clinical Guide to Laboratory Tests. 2nd ed. W B Saunders Co, PA, USA; 1990

41. Felger I, Tavul L, Beck HP. Plasmodium falciparum: a rapid technique for genotyping the merozoite surface protein 2. Exp Parasitol. 1993;77(3):372-375. 
42. Farcas GA, Soeller R, Zhong K, Zahirieh A, Kain KC. Real-time polymerase chain reaction assay for the rapid detection and characterization of chloroquine-resistant Plasmodium falciparum malaria in returned travelers. Clin Infect Dis. 2006;42(5):622-627.

43. Huaman MC, Roncal N, Nakazawa S, et al. Polymorphism of the Plasmodium falciparum multidrug resistance and chloroquine resistance transporter genes and in vitro susceptibility to aminoquinolines in isolates from the Peruvian Amazon. Am J Trop Med Hyg. 2004;70(5):461-466.
44. Lo JB, Appel LE, Herbig SM, McCray SB, Thombre AG. Formulation design and pharmaceutical development of a novel controlled release form of azithromycin for single-dose therapy. Drug Dev Ind Pharm. 2009;35(12):1522-1529.

\section{Publish your work in this journal}

Research and Reports in Tropical Medicine is an international, peerreviewed, open access journal publishing original research, case reports, editorials, reviews and commentaries on all areas of tropical medicine, including: Diseases and medicine in tropical regions; Entomology; Epidemiology; Health economics issues; Infectious disease; Laboratory

Submit your manuscript here: https://www.dovepress.com/research-and-reports-in-tropical-medicine-journal

science and new technology in tropical medicine; Parasitology; Public health medicine/health care policy in tropical regions; and Microbiology. The manuscript management system is completely online and includes a very quick and fair peer-review system. Visit http://www.dovepress. com/testimonials.php to read real quotes from published authors. 